\title{
Global transcriptome analysis of two ameiotic1 alleles in maize anthers: defining steps in meiotic entry and progression through prophase I
}

\author{
Guo-Ling Nan ${ }^{1 *}$, Arnaud Ronceret ${ }^{2}$, Rachel C Wang ${ }^{2,3}$, John F Fernandes ${ }^{1}$, W Zacheus Cande ${ }^{2}$ and Virginia Walbot ${ }^{1}$
}

\begin{abstract}
Background: Developmental cues to start meiosis occur late in plants. Ameiotic1 (Am1) encodes a plant-specific nuclear protein (AM1) required for meiotic entry and progression through early prophase I. Pollen mother cells (PMCs) remain mitotic in most am1 mutants including am 1-489, while am1-pral permits meiotic entry but PMCs arrest at the leptotene/zygotene (L/Z) transition, defining the roles of AM1 protein in two distinct steps of meiosis. To gain more insights into the roles of AM1 in the transcriptional pre-meiotic and meiotic programs, we report here an in depth analysis of gene expression alterations in carefully staged anthers at $1 \mathrm{~mm}$ (meiotic entry) and 1.5 $\mathrm{mm}(\mathrm{L} / \mathrm{Z})$ caused by each of these $\mathrm{am} 1$ alleles.

Results: $1.0 \mathrm{~mm}$ and $1.5 \mathrm{~mm}$ anthers of am 1-489 and am 1-pral were profiled in comparison to fertile siblings on Agilent ${ }^{\circledR} 4 \times 44 \mathrm{~K}$ microarrays. Both am 1-489 and am 1-pral anthers are cytologically normal at $1.0 \mathrm{~mm}$ and show moderate transcriptome alterations. At the $1.5-\mathrm{mm}$ stage both mutants are aberrant cytologically, and show more drastic transcriptome changes. There are substantially more absolute On/Off and twice as many differentially expressed genes (sterile versus fertile) in am1-489 than in am1-pral. At $1.5 \mathrm{~mm}$ a total of 4,418 genes are up- or down-regulated in either am1-489 or am1-pral anthers. These are predominantly stage-specific transcripts. Many putative meiosis-related genes were found among them including a small subset of allele-specific, mis-regulated genes specific to the PMCs. Nearly $60 \%$ of transcriptome changes in the set of transcripts mis-regulated in both mutants $(\mathrm{N}=530)$ are enriched in PMCs, and only $1 \%$ are enriched in the tapetal cell transcriptome. All array data reported herein will be deposited and accessible at MaizeGDB http://www.maizegdb.org/.
\end{abstract}

Conclusions: Our analysis of anther transcriptome modulations by two distinct am1 alleles, am 1-489 and am1-pral, redefines the role of AM1 as a modulator of expression of a subset of meiotic genes, important for meiotic progression and provided stage-specific insights into the genetic networks associated with meiotic entry and early prophase I progression.

Keywords: meiosis, meiocytes, transcriptomes, leptotene/zygotene transition, pollen mother cells

\section{Background}

During sexual reproduction meiosis insures that progeny receive half their genetic information from each parent, thus maintaining the correct ploidy from generation to generation. Many genes essential for meiosis are highly conserved in fungi, invertebrates, mammals, and plants. On the contrary, mechanisms governing the initiation of meiosis are diverse [1]. Unlike animals, plants lack a

\footnotetext{
* Correspondence: gnan@stanford.edu

'Department of Biology, Stanford University, Stanford, CA 94305, USA

Full list of author information is available at the end of the article
}

germ line pre-determined early in development. Therefore, understanding the molecular changes that specify the archesporial cells, the progenitors of meiotic cells, is crucial in defining the network of cellular processes leading to a successful switch from mitosis to meiosis.

Flowering is a late step in plant development, and nearly all floral cells are somatic. Mutants defective in the reproductive cells often have no or few defects in the soma and vice versa; once specified, the pre-meiotic cells can proliferate mitotically and then differentiate for meiosis successfully even when the surrounding somatic
C Biomed Central

() 2011 Nan et al; licensee BioMed Central Ltd. This is an Open Access article distributed under the terms of the Creative Commons Attribution License (http://creativecommons.org/licenses/by/2.0), which permits unrestricted use, distribution, and reproduction in any medium, provided the original work is properly cited. 
tissue is abnormal [2]. In Angiosperms meiotic cells originate from a handful of pluripotent somatic cells, derived from the L2 layer (L2-d) of a floral meristem. In maize (Zea mays L.), a few archesporial cells - the precursors of meiotically competent PMCs - are cytologically distinguishable by their central locular location and rapid enlargement when there are approximately 20 L2$\mathrm{d}$ cells in locules of 150-170 $\mu \mathrm{m}$ anthers [3] (Figure 1a). Archesporial cells proliferate mitotically for several days (Figure 1b) then pause for 3 days as they mature into PMCs and functional meiocytes; concomitantly, the maize anthers grow from $1 \mathrm{~mm}$ to $1.5 \mathrm{~mm}$ (Figures $1 \mathrm{c}$ and $1 \mathrm{j})$. L2-d cells that do not differentiate as archesporial cells form 3 somatic layers, each of a single cell type, that encircle the pre-meiotic population (Figure 1c). It is presently unclear how L2-d cells are programmed to be pre-meiotic within anthers or how this identity is retained during the mitotic divisions prior to PMC maturation. By $1.5 \mathrm{~mm}$, prophase I has started and completion of meiosis depends on the correct expression of many genes $[4,5]$. Although archesporial cell divisions are asynchronous, maize meiosis is highly synchronized, likely facilitated by plasmodesmatal (cytoplasmic) connections among the PMCs.

Our focus is to understand the maturation of PMCs present in $1.0 \mathrm{~mm}$ anthers into meiocytes, that is, what processes are required for the cessation of mitosis, acquisition of meiotic competence, and initiation of meiosis? Many genes have been identified in flowering plants that are required for normal anther differentiation, but we are interested in defining the steps leading towards meiosis once the normal population of somatic and PMC cells are present. Several lines of evidence indicate that meiosis is set up as early as the pre-meiotic interphase [6-8], during the three day period of PMC maturation in maize anthers. Additionally, there may be differentiation steps preceding this stage that are not visualized cytologically.

Our entry point into analyzing meiotic competence is AM1; this is a maize nuclear protein required for normal PMC maturation [9], and it is necessary for both meiotic initiation and progression through early prophase I [10]. The actual roles of AM1 in the progression of meiosis at either the premeiotic/meiotic or the $\mathrm{L} / \mathrm{Z}$ transition are still unclear at the molecular level. The closest homologs to AM1 are OsAM1 in rice [11] and SWI1/DYAD in Arabidopsis thaliana [12,13], but this gene is absent from both fungal and animal genomes. An analysis of double mutant combinations showed that $A m 1$ is epistatic to many meiotic genes responsible for homologous chromosome pairing, including afd $1, d v 1$, $m s 43$, and $m s 28$ [14]; additional meiotic processes impacted in am1 mutants include regulation of sister chromatid cohesion, telomere bouquet formation, recombination, synapsis, microtubule organization, and expression of other meiotic genes, particularly those acting during early prophase I [10].

Multiple am1 alleles have been distinguished cytologically $[14,15]$, and all homozygotes are male-sterile. In all but one allelic state (am1-praI), central locular cells with PMC cellular anatomy undergo mitosis rather than meiosis. For example, the am1-489 allele contains a $\mathrm{Mu}$ insertion in an exon near the 3'-end; although the allele is transcribed, no protein is detected in mutant anthers [10]. The am1-praI allele encodes a semi-functional protein with a single amino acid substitution (R358W); the protein supports meiotic entry but PMCs fail to progress normally. In fertile maize, AM1 is expressed premeiotically and later loaded onto chromosomes during early prophase I; the defective AM1-PRAI protein remained mainly dispersed in nuclei and meiosis stalls at the $\mathrm{L} / \mathrm{Z}$ transition [10]. The $\mathrm{L} / \mathrm{Z}$ transition is a major step in meiotic progression during which pairing of homologous chromosomes is initiated as telomeres cluster on the nuclear envelope and double strand breaks are made as homologous recombination proceeds [16]. The am1-praI allele demonstrates that the L/Z transition is tightly regulated in plants, and it allows us to analyze this critical meiotic step in maize. The precise phenotypes of mutants are species-specific, but in each case AM1 and its homologs play a role in the regulation of early meiotic events. OsAM1 from rice [11] has a similar domain organization as maize, however, the SWI1/DYAD protein of Arabidopsis lacks N- and Cterminal domains found in AM1 and shares only $31 \%$ similarity in the central conserved PHD finger domain $[12,13]$. An RNAi inhibition of OsAm1 results in meiocytes that reach leptotene, similar to the maize am1praI mutant [11]. Aberrant SWI1/DYAD1 proteins in Arabidopsis affect chromosome structure and cohesion during meiosis to various extents in both anthers and ovules $[12,13,17]$ likely through meiotic chromosome remodeling [18]. The sister chromatids segregate unevenly during meiosis in swi1-1/dyad anthers, while in the ovule, meiosis is replaced by mitosis. Arabidopsis with specific $S W I 1 / D Y A D 1$ alleles show a small proportion of unreduced diploid gametes indicative of a meiotic or post-meiotic failure. This phenotype represents the first step (apomeiosis) to generate apomictic progeny, a novel prospect in plant breeding in which the progeny genotype is identical to the parent (meiotic failure class) or identical to a single meiotic product [19].

To better understand the required steps that normally occur during PMC maturation in preparation for meiosis and for progression through the critical L/Z transition, we compared the anther transcriptomes of mitotic am1-489 and L/Z meiotic arrest am1-praI lines using a custom Agilent $4 \times 44 \mathrm{~K}$ microarray. Although $a m 1$ 
(a)

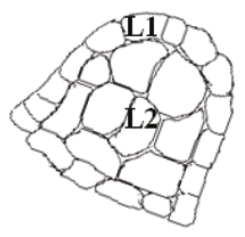

(b)

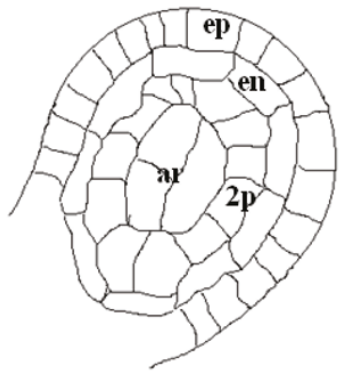

(c)

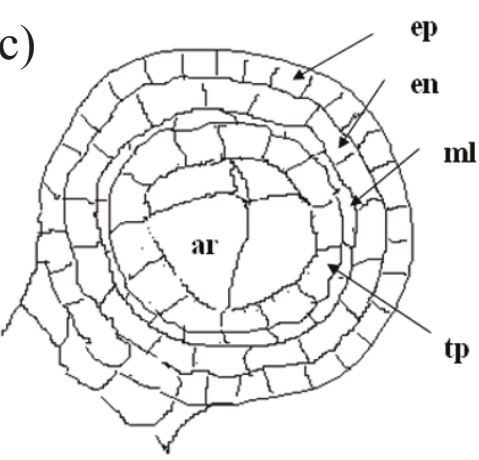

$0.1 \mathrm{~mm}$

$0.3 \mathrm{~mm}$

$1.0 \mathrm{~mm}$

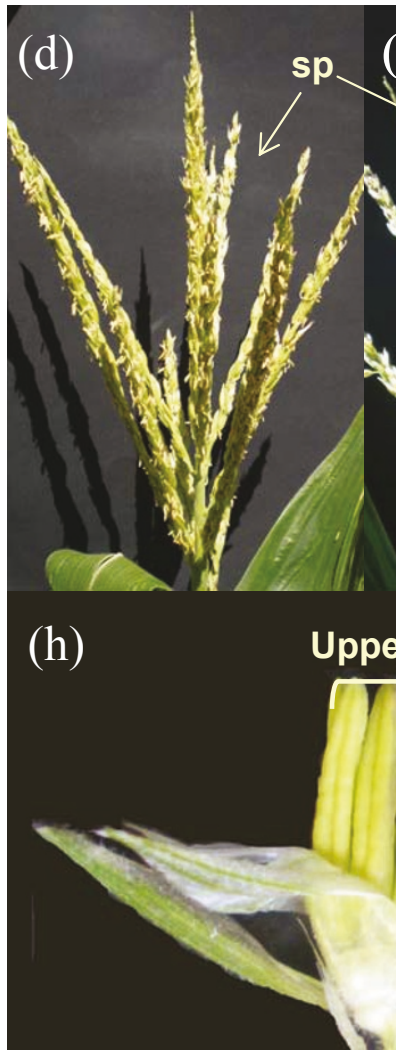

(e)

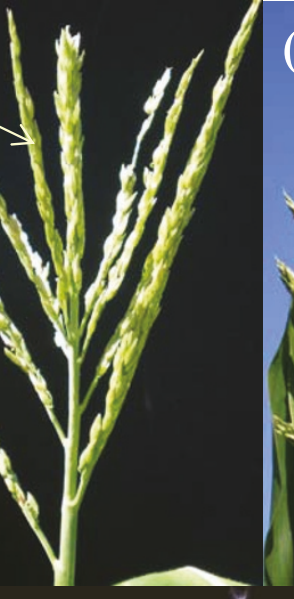

(f)

(g)
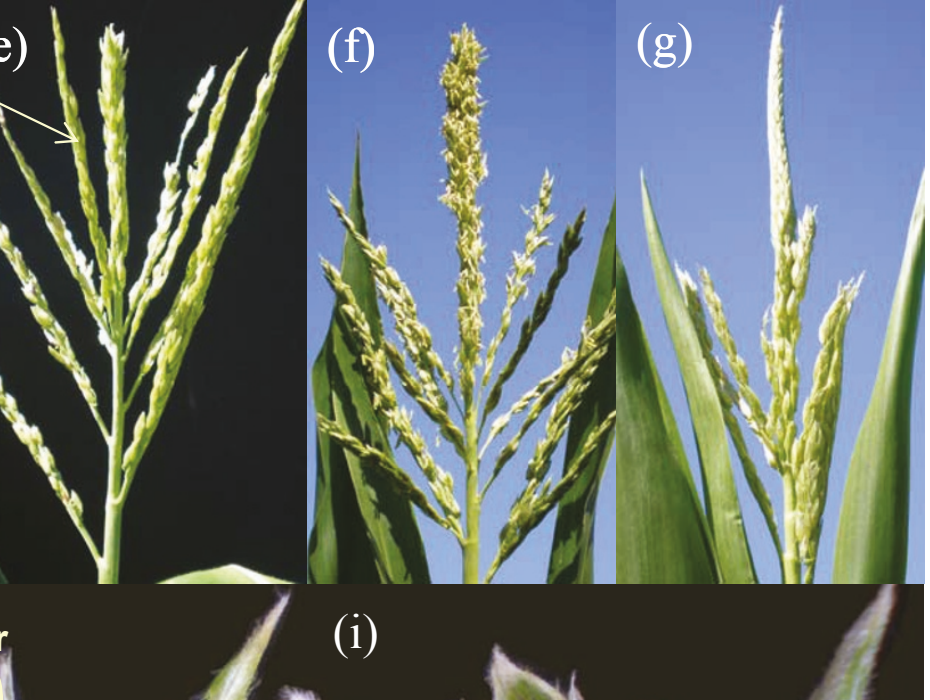

(i)
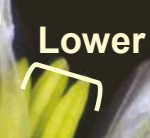

(j)

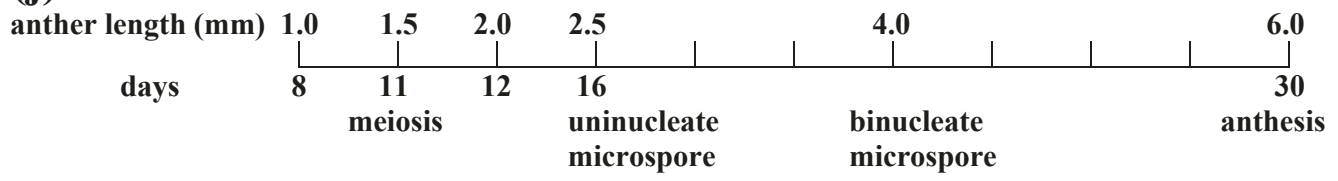

Figure 1 Maize tassel and anther development. Fertile maize anthers contain four locules. At $\sim 0.1 \mathrm{~mm}$ there are about 50 cells in each locule. The line drawing of a transverse section (a) shows that the L2-derived (L2-d) cells are distinguishable from the L1-derived epidermis (ep) within a locule. At $0.3 \mathrm{~mm}$ (b) the L2-d has developed into endothecium (en), secondary parietal (2p) and archesporial cell types (ar). At $1.0 \mathrm{~mm}$ (c) middle layer $(\mathrm{ml})$ and tapetum (tp) are apparent after a periclinal division of the $2 \mathrm{p}$ layer cells. Apart from the general morphology of no anther exertion, the mature tassel on the male-sterile am1-pral plant (e) is highly similar to a fertile sibling tassel (d) with the same number of tassel branches. In contrast, the am 1-489 tassels (g) have fewer side branches (5-6) than fertile siblings (f). The individual reproductive units on the tassel are spikelets (sp). There are two florets in each spikelet, and each floret contains 3 anthers (h). The adaxial, upper florets used in the array experiment are developmentally 1 day ahead of the abaxial, lower florets. Anthers on a male sterile am 1-pral plant (i) can reach 4-5 mm in length before they shrivel and degenerate; am 1-489 anthers show growth arrest at 2-2.5 mm (data not shown). Based on cytological evidence and published results, anther sizes and the developmental timeline showing days after locular primordium initiation are diagrammed (j). 
mutants affect both male and female meiosis, anthers were chosen because they are much easier to dissect than the female floral tissue and because comprehensive transcriptome studies of normal maize anther development are already available on this array platform [20-22].

\section{Results}

\section{Development and morphology of am 1 mutant tassels}

To identify stages of anther development in fertile and male-sterile siblings relevant for this study, developmental progression was carefully followed for the two backgrounds harboring the am1-praI and am1-489 alleles. The male inflorescence (tassel) on a fertile maize plant bears hundreds of spikelets as shown in Figures $1 \mathrm{~d}$ and 1f. When tassels reach maturity, the side branches held upright along the main spike relax to a lateral position, and pollen is shed from exerted anthers. The external morphology of am1-praI tassels (Figure 1e) is highly similar to a fertile sibling (Figure 1d) with the same number of tassel branches (8-10). In contrast, am1-489 tassels (Figure 1g) have fewer side branches (5-6) than their fertile siblings (8-10, Figure 1f). Delayed tassel development in am1-489 plants was also observed, because tassel branches remained upright about 5-7 days longer than in fertile siblings; tassels on am1-praI plants switched from upright to lateral simultaneously with fertile siblings.

Each spikelet contains two florets; each floret contains 3 anthers (Figure 1h) and each anther contains 4 locules. The upper floret is generally advanced 1 day relative to the lower floret. In our array experiment, only anthers from the upper florets were collected, and all measurements refer to this floret. Many male sterile mutants of maize with pre-meiotic defects exhibit delayed tassel maturation and anther growth arrest at about $2 \mathrm{~mm}$ (V. Walbot, unpublished data), that is, a failure to sustain anther growth during the three week period that follows completion of meiosis in fertile plants. Male sterile am1-praI anthers continue to grow and reach 4 to $5 \mathrm{~mm}$ in length (Figure 1i) at approximately the same time as fertile siblings. This indicates that the somatic cell layers of the am1-praI mutant anthers can sustain growth despite meiotic arrest. Sterile am1-praI anther locules are plump (not shown) until right before they degenerate (Figure $1 \mathrm{~g}$ ). In contrast, am1-489 anthers arrest at about $2 \mathrm{~mm}$, the locules collapse, and anthers degenerate early as is typical of most ameiotic1 and other pre-meiotic male sterile mutants $[9,22]$. We conclude that somatic anther growth beyond $2 \mathrm{~mm}$ requires the presence of functional PMCs. We hypothesize that somatic anther tissues in am1-praI anthers perceive cues such as meiotic entry by the PMCs but progression through prophase I is not required to maintain anther growth.

\section{Cytological staging}

Anthers were collected, fixed and later stained with acetocarmine to determine the cytological stage of PMCs in 1.0, 1.5 and $2.0 \mathrm{~mm}$ anthers (Figure 2). Both the 1.0 mm am1-489 and am1-praI PMCs were at premeiotic interphase at the $1.0 \mathrm{~mm}$ stage (Figure 2a) and cytologically normal. Archesporial cells in fertile plants finish most if not all the pre-meiotic mitotic divisions just before the $1.0 \mathrm{~mm}$ PMC stage, but the cells continue to expand in size from 1.0 to $1.5 \mathrm{~mm}$ as they mature [3]. Most PMCs of $1.0 \mathrm{~mm}$ fertile anthers were at interphase, but a few had advanced to early leptotene (Figure 2a). At $1.5 \mathrm{~mm}$, the fertile PMCs are definitely in meiosis and achieve zygotene synchronously (Figure 2a), while the PMCs in am1-489 were found at various stages of mitosis (unsynchronized) with twenty unsynapsed chromosomes (Figure 2a). At $2.0 \mathrm{~mm}$ am1-489 PMCs continued one or more rounds of mitosis (Figure 2a) as previously reported [15].

am1-praI PMCs are delayed in maturation and remained at interphase (Figure 2a) at $1.5 \mathrm{~mm}$. Eventually they start meiosis synchronously by the $2.0 \mathrm{~mm}$ stage (Figure $2 \mathrm{a}$ ), about $18 \mathrm{~h}$ after the normal $1.5 \mathrm{~mm}$ stage (Figure 2b, [20]; the PMCs then arrest at the L/Z transition. Therefore, am1-praI PMCs are delayed in meiotic entry and progress more slowly through the initial meiotic stages.

\section{On/Off transcriptome differences in fertile and mutant anthers}

Probes were scored as present (On) or absent (Off) as described in Methods. Maize anthers express an astonishing number of genes: the Agilent $4 \times 44 \mathrm{~K}$ maize array has routinely detected expression of $\sim 30,000$ genes in both $1.0 \mathrm{~mm}$ and $1.5 \mathrm{~mm}$ anthers [21,22]. Because the two am 1 alleles examined here are in different genetic backgrounds (see Methods) and maize inbred lines exhibit high levels of gene presence/absence and copy number variation [23] we first investigated the congruence of anther transcriptomes between the fertile siblings in these two lines. The majority of the transcriptomes $(91 \%$ at $1.0 \mathrm{~mm}$ and $88 \%$ at $1.5 \mathrm{~mm})$ are shared between the two fertile backgrounds (Table 1). Average variation of $\sim 7 \%$ in gene content is reported for inbred lines [23], and we conclude that many of the differences observed in the two backgrounds are attributable to maize diversity. To minimize background effects in the On/Off analysis of gene expression, we have compared mutant anther transcriptomes directly to fertile siblings.

At $1.0 \mathrm{~mm}$ am1-489 anthers are cytologically similar to fertile siblings; however, they are missing 2\% (484/ 30,070 ) of the transcripts present in fertile siblings, which is above the estimated $0.13 \%$ false discovery rate (see Methods). Additionally, 4\% $(1,208)$ are ectopically 


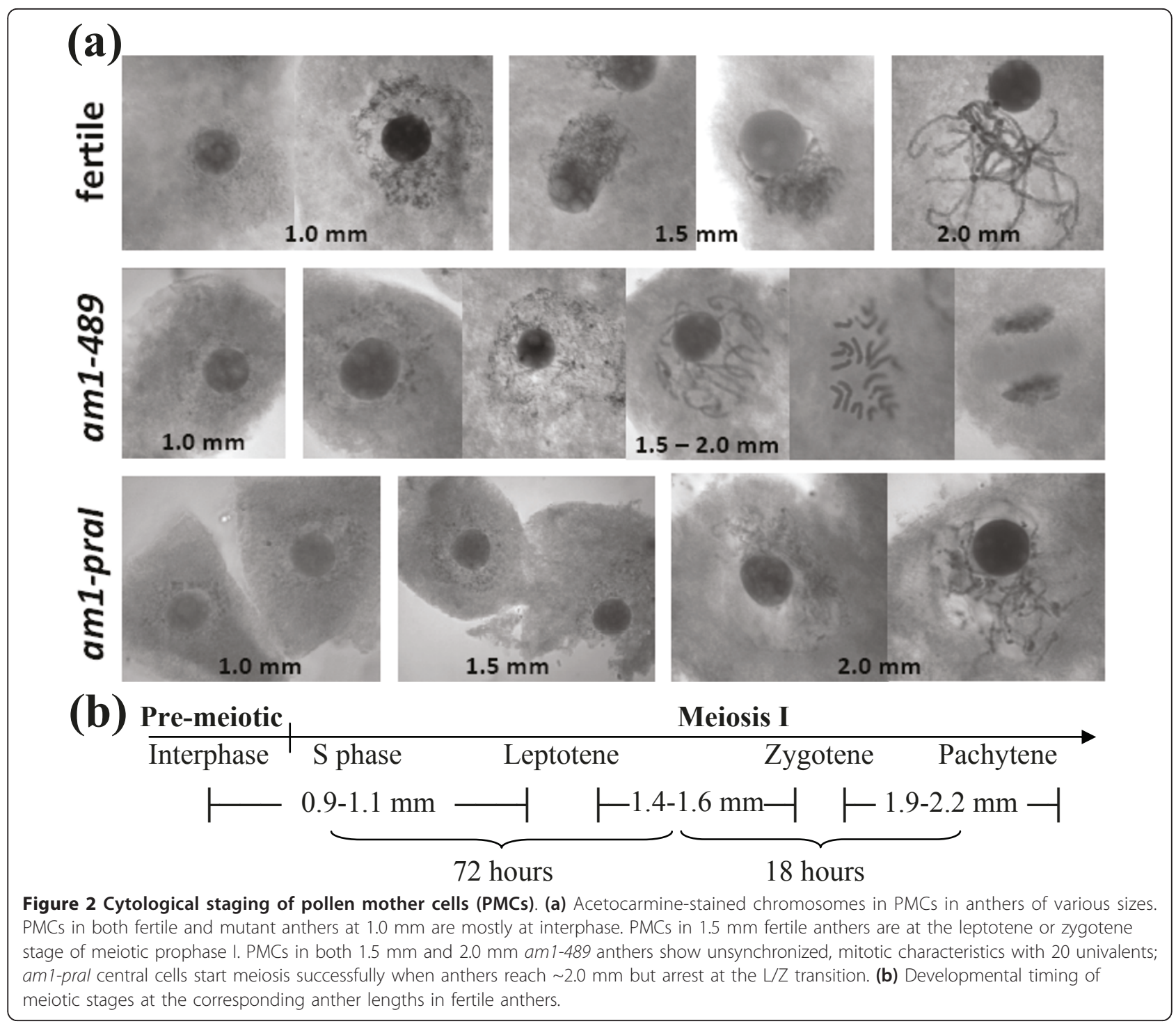

expressed compared to fertile siblings (Table 1). These ectopically expressed genes include those that contribute to continued mitosis by the PMCs of am1-489 anthers. At $1.0 \mathrm{~mm}$ am1-praI anthers are also similar to fertile cytologically, but there are $\sim 10 \%$ fewer $[(31,280-28,104)$ / $31,280]$ transcript types and ectopic expression of 80 genes $(0.26 \%)$. Some of these transcriptome differences at $1.0 \mathrm{~mm}$ could reflect linkage disequilibrium (allelic variation between fertile and sibling sterile plants at loci linked to am1 alleles) or phenotypes too subtle to visualize by microscopy. As is explicated below, the major contributor to the transcriptome difference in am1-praI is the developmental delay in this mutant.

PMCs in $1.5 \mathrm{~mm}$ fertile anthers are at early prophase I between the leptotene and zygotene stages, somatic cells have differentiated, and somatic cell division has slowed. At $1.5 \mathrm{~mm}$ the more severe am1-489 anthers are missing more than 3,700 transcripts $(\sim 13 \%)$ expressed in fertile siblings (Table 1). Among these, 3,487 are also expressed in both am1-praI mutant and fertile siblings, hence among the thousands of loss-of-expression cases should be genes involved in meiotic entry. In contrast, just over 500 (<2\%) genes are off in am1-praI compared to fertile siblings (Table 1 ). The transcriptome data support the cytological observation of delayed meiotic entry in am1-praI, because $80 \%(2,634)$ of the transcripts missing at $1.0 \mathrm{~mm}$ are expressed by $1.5 \mathrm{~mm}$. A linkage tree of the global transcriptome including all 8 sample types also demonstrated the transcriptomes are most divergent between the two backgrounds while the transcriptome differences between mutant and fertile samples at $1.0 \mathrm{~mm}$ are the least. In both backgrounds, the transcriptome of the mutant samples is more distinctive from fertile at $1.5 \mathrm{~mm}$ than at $1.0 \mathrm{~mm}$ 
Table 1 Numbers of expressed genes with various patterns

\begin{tabular}{cccccccccc}
\hline \multicolumn{3}{c}{$\mathbf{1 . 0} \mathbf{~ m m}$} \\
\hline 4895 & 489F & praS & praF & Genes & 4895 & 489F & pras & praF & Genes \\
\hline Off & Off & Off & On & 856 & Off & Off & Off & On & 389 \\
Off & Off & On & Off & 37 & Off & Off & On & Off & 1018 \\
Off & Off & On & On & 462 & Off & Off & On & On & 2519 \\
Off & On & Off & Off & 135 & Off & On & Off & Off & 150 \\
Off & On & Off & On & $\mathbf{2 1 1}$ & Off & On & Off & On & $\mathbf{5 7}$ \\
Off & On & On & Off & 3 & Off & On & On & Off & 81 \\
Off & On & On & On & $\mathbf{1 3 5}$ & Off & On & On & On & $\mathbf{3 4 8 7}$ \\
On & Off & Off & Off & 491 & On & Off & Off & Off & 64 \\
On & Off & Off & On & 469 & On & Off & Off & On & 21 \\
On & Off & On & Off & 17 & On & Off & On & Off & 31 \\
On & Off & On & On & 231 & On & Off & On & On & 216 \\
On & On & Off & Off & 647 & On & On & Off & Off & 242 \\
On & On & Off & On & $\mathbf{1 7 2 0}$ & On & On & Off & On & $\mathbf{6 0}$ \\
On & On & On & Off & 23 & On & On & On & Off & 67 \\
On & On & On & On & $\mathbf{2 7 1 9 6}$ & On & On & On & On & $\mathbf{2 4 4 6 8}$ \\
\hline 489:
\end{tabular}

489: am1-489; pra: am1-pral; F: fertile; S: sterile. Bold values are the common expressed sets in both 489 and pra backgrounds.

(Additional File 1). Hence, it is important to exclude background difference before comparing the two alleles.

The lists of On/Off genes were evaluated for the presence of known meiosis-associated genes, but none were found. Thus although the am1 mutant alleles impact expression of $\sim 10 \%$ of maize genes through ectopic expression and loss-of expression, these transcriptome differences must relate primarily to somatic cell processes. This demonstrates that meiotic genes are expressed in sterile $a m 1$ anthers but their expression levels could still be affected.

\section{Up- or down-regulated genes between stages or between alleles}

In addition to On/Off differences, we also evaluated transcript types that were expressed (On) and at least 1.5fold distinct from the comparator with a p-value $<0.05$ (see Methods). To minimize false discovery resulting from background differences while comparing the two mutant anther types, only transcript types detected in both fertile backgrounds (common fertile set: 29,262 at $1.0 \mathrm{~mm}$ and 28,072 at $1.5 \mathrm{~mm}$; highlighted in Table 1) were used in the evaluation of up- or down-regulated genes. Both mutant anthers had about 4 times more genes differentially expressed at $1.5 \mathrm{~mm}$ than at $1.0 \mathrm{~mm}$ (Figure 3a); most transcripts are stage-specific confirming the distinctive properties of these two developmental stages [20]. The greater transcriptome abnormalities at $1.5 \mathrm{~mm}$ parallel the more aberrant mutant phenotypes at this stage. A subset of these transcripts is likely essential for entry and progression through early meiosis. The am1-489 mutants had about twice as many genes up- or down-regulated than am1-praI at $1.5 \mathrm{~mm}$ (Figure 3b), confirming molecular consequences of the more severe phenotype of am1-489. The 3,358 differentially expressed genes unique to am1-489, regardless of stage, are likely involved in meiotic entry or conversely highlight genes involved in the suppression of mitosis. The majority of these transcriptome differences $(2,613,78 \%)$ are found at $1.5 \mathrm{~mm}$, including six meiotic genes, i.e., MEL1, SPO111, OSD1a, RPA70 (RPA1a), PS1, and MSH5.

In addition to the numerous allele-specific, differentially regulated genes, there are a total of 530 differentially expressed genes common to am1-489 and am1praI at the $1.5 \mathrm{~mm}$ stage (Figure 3c). These include the non-redundant 468 genes that are differentially expressed in both (Figure 3c) and 62 oppositely regulated transcripts ("up versus not up" or "down versus not down"). Genes mis-regulated in both mutants at both stages (8 overlapping areas in Figure 3 ) are good candidates for common transcriptome responses of $a m 1$ mutant anthers relating to progression through the $\mathrm{L} / \mathrm{Z}$ transition. The non-redundant set of 468 genes found at $1.5 \mathrm{~mm}$ is of particular interest, because this is a critical point of meiotic progression. Maize homologs of well known meiotic genes, e.g., Skp1B, Zip4/Spo22-like, Rad54-like, and meiosis-specific cyclins [24-32], show transcriptional mis-regulation in the $a m 1$ mutants.

Based on cytological evidence, development of PMCs in am1-praI is delayed then arrests while PMCs in am1489 anthers undergo a mitotic division instead of a meiotic one. Therefore, the transcriptome changes in am1-489 anthers compared to fertile at $1.0 \mathrm{~mm}$ might also be important for meiotic entry. Afd1 (Rec8/Rad21 homolog), and $R P A 70$, for example, are moderately down-regulated in am1-489 at $1.0 \mathrm{~mm}$ but not down in am1-praI at $1.5 \mathrm{~mm}$. Homolog of $A f d 1$ encodes protein associated with the cohesion complex, which establishes sister chromatid cohesion [33-35], while RPA70 is implicated in replication, repair, and transcription [36]. We also noted an RNA helicase SDE3 in this group, known for its role in post-transcriptional gene silencing via RNAi [37] and shown to be associated with meiosis in worms, flies, and mammals [38-40]. A heat map of all the meiotic genes included on this array (a total of 78 probes spanning 45 genes) is shown in Additional File 2.

Our results indicate that AM1 protein attenuates the expression level of many meiotic genes and other somatic genes that are crucial for anther maturation. Anther development is delayed (am1-praI) and ultimately stalled, causing male sterility.

\section{Data validation}

A pilot array experiment was conducted on the same array platform prior to the study reported here. Anthers from 
(a)

(b)
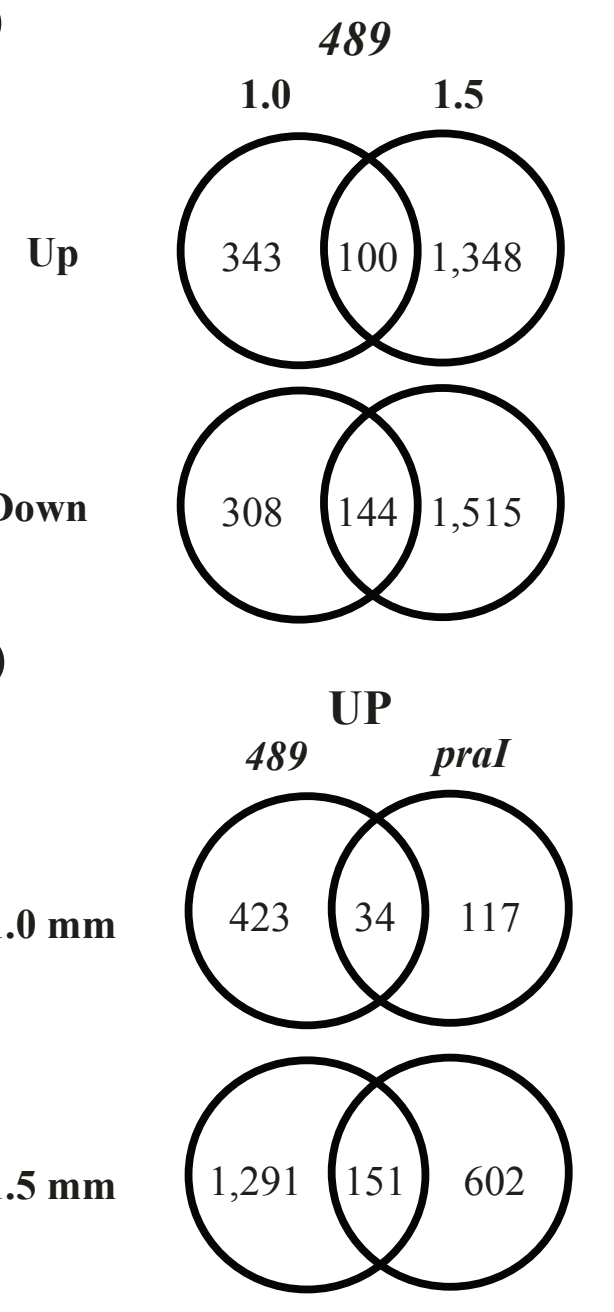
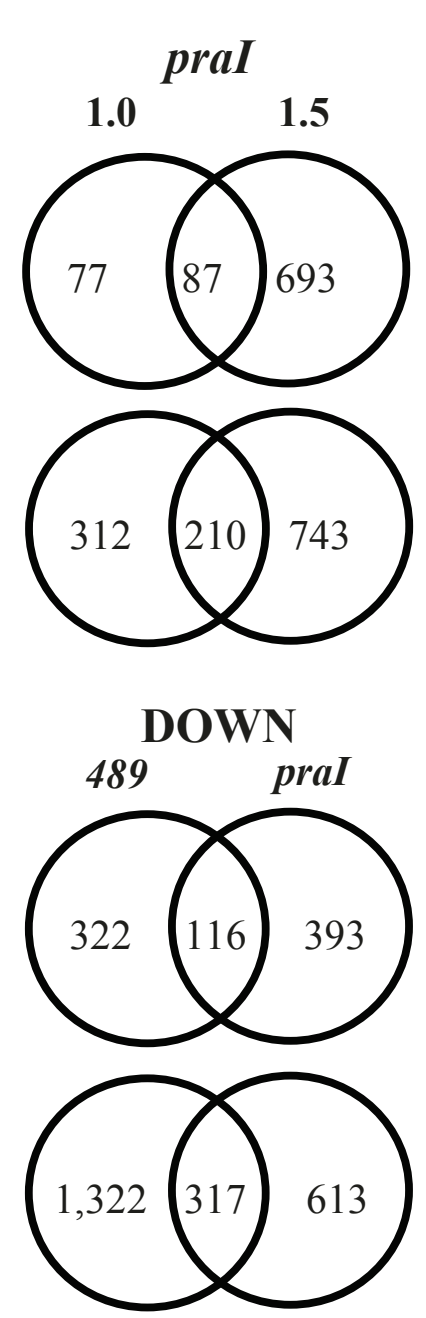

(c)

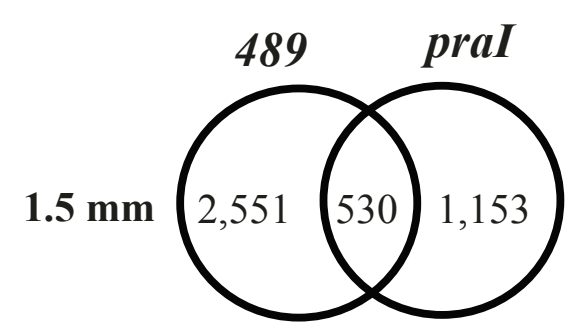

Figure 3 Differential expression between mutant and fertile anthers. Venn diagrams of up- or down-regulated genes in am 1 alleles compared to the common fertile dataset. Number of transcripts unique to a stage or allele or expressed in common: (a) between two stages; (b) between alleles; and (c) comparison of the two mutant alleles at $1.5 \mathrm{~mm}$, showing the number of differentially expressed transcripts unique to each allele and the common set (including the oppositely regulated with duplicates removed).

families segregating for am1-489 and am1-praI were used in the pilot experiment and only male sterile anthers at 1.0 $\mathrm{mm}$ and $1.5 \mathrm{~mm}$ with 4 biological pools for each sample type were included. We compared data from the pilot experiment and found more than $90 \%$ of the pilot data corroborated results presented here (Additional File 3).

To further validate quantification and classification of key transcripts, a panel of 11 meiosis-associated genes including $A m 1$ was analyzed by qRT (quantitative RTPCR). Ten of them showed congruent results with the array data (Table 2 and Additional File 4). The one exceptional transcript (Spo11-1) was scored as borderline up-regulated ( 1.5 -fold criterion, $\log 2=0.6)$ in am1489 mutant versus fertile at $1.5 \mathrm{~mm}$ on the array but was not significantly changed based on qRT results. Notably we checked the expression level of $A m 1$ itself. 
Table 2 A panel of meiotic genes and their expression patterns in ameiotic1 (am1) anthers

\begin{tabular}{|c|c|c|c|c|c|}
\hline Maize Gene ID & Names & Homolog & Stage & $\begin{array}{c}\text { qRT } \\
\text { Verified }\end{array}$ & Differentially Expressed \\
\hline GRMZM2G075563 & Ms5 & plant only & various & & down in $a m 1-489$ at $1.5 \mathrm{~mm}$ \\
\hline GRMZM2G059037 & Afd1 & $\operatorname{Rec} 8 / \operatorname{Rad} 21$ & prophase I & $\sqrt{ }$ & $\begin{array}{l}\text { down in am1-489 no change in am 1-pral at both } \\
\text { stages }\end{array}$ \\
\hline GRMZM5G883855 & Am1 & plant only & $\begin{array}{l}\text { pre- } \\
\text { meiotic }\end{array}$ & $\sqrt{ }$ & down in am1-489; up in am1-pral at both stages \\
\hline GRMZM2G109618 & Dmcl & Dmcl & prophase I & $\sqrt{ }$ & down in both mutant alleles at $1.5 \mathrm{~mm}$ \\
\hline GRMZM2G408897 & Mmd1 & plant only & early-late & & down in both mutant alleles at $1.5 \mathrm{~mm}$ \\
\hline GRMZM2G060394 & SkplA & Skp1A & prophase I & $\sqrt{ }$ & significantly down in both mutant alleles at $1.5 \mathrm{~mm}$ \\
\hline GRMZM2G032562 & Skp1B & Skp1B & & $\sqrt{ }$ & significantly down in both mutant alleles at $1.5 \mathrm{~mm}$ \\
\hline GRMZM2G143590 & Zyp1 & Zipl & prophase I & $\sqrt{ }$ & down in both mutant alleles at both stages \\
\hline GRMZM2G083138 & Rad54-like & Rad54-like & prophase I & $\sqrt{ }$ & down in both mutant alleles, particularly at $1.5 \mathrm{~mm}$ \\
\hline GRMZM2G100103 & Phs1 & $\operatorname{Rec} 114$ & prophase I & & low or no expression in all \\
\hline GRMZM2G129913 & Spo11-1 & Spo11 & prophase I & $\mathrm{nc}$ & marginal changes \\
\hline $\begin{array}{l}\text { GRMZM2G454838/ } \\
\text { GRMZM2G328795 }\end{array}$ & $\begin{array}{l}\text { Zip4/Spo22- } \\
\text { like }\end{array}$ & $\begin{array}{l}\text { Zip4/Spo22- } \\
\text { like }\end{array}$ & prophase I & & down in both mutant \\
\hline GRMZM5G883855 & $A m / 1$ & Mei2 & prophase I & & no changes \\
\hline GRMZM2G102242 & Mnd1 & Mnd1 & prophase I & & no changes \\
\hline GRMZM2G308884 & Prd1 & Mei1 & prophase I & & no changes \\
\hline GRMZM2G121543 & Rad51A & Rad51 & prophase I & $\sqrt{ }$ & no changes \\
\hline GRMZM2G084762 & $\operatorname{Rad51A2}$ & $\operatorname{Rad51A2}$ & prophase I & $\sqrt{ }$ & no changes \\
\hline GRMZM2G115013 & RPA70 & RPATa & various & $\sqrt{ }$ & down in am $1-489$ at 1.0 and $1.5 \mathrm{~mm}$ \\
\hline GRMZM2G315902 & Mlh3 & Mlh3 & prophase I & & no changes or not significant \\
\hline GRMZM2G055899 & Pairla & plant only & $\begin{array}{l}\text { pre- } \\
\text { meiotic }\end{array}$ & & not significant \\
\hline GRMZM2G056075 & Msh5 & Msh5 & various & & not significant except up in am 1-489 at $1.5 \mathrm{~mm}$ \\
\hline GRMZM2G457370 & Agol & Ago 1 & $\begin{array}{l}\text { pre- } \\
\text { meiotic }\end{array}$ & & up in both mutant alleles at both stages \\
\hline
\end{tabular}

$\sqrt{ }: \mathrm{qRT}$ analyses found the same direction of regulation and approximately the same magnitude of change as calculated from the microarray analysis; nc: qRT and array results were non-congruent.

The qRT analysis confirms the over-expression of the transcript in am1-praI in $1.5 \mathrm{~mm}$ anthers observed in the microarray data. It is likely that the temporal arrest at the L/Z stage and the inefficient loading of AM1PRAI onto the chromosomes, when Am1-praI is highly expressed, lead to message accumulation in meiocytes. The increased transcript abundance is also reflected in at least 2 times higher levels of AM1-PRAI protein in tassels containing 1.0-3.0 $\mathrm{mm}$ anthers than in wild type siblings at these stages (Additional File 5).

\section{Gene ontology (GO) annotation of differentially regulated transcripts}

GO terms were assigned using Agbase http://www. agbase.msstate.edu, where more than $50 \%$ of the probes have one or more terms assigned. Figure 4 illustrates the classification of differential transcripts excluding the unknown category, which are included in the list of gene counts in Additional File 6. Several functional groups are prominent. Genes with catalytic activity and transporter activity are affected at 1.0 and $1.5 \mathrm{~mm}$ in both am1-489 and am1-praI anthers. At the pre-meiotic
$1.0 \mathrm{~mm}$ stage, genes with hydrolase activity or nucleotide binding accounted for $\sim 30 \%$ of the genes with known functions. These groups are likely critical in PMCs at interphase when cells are preparing for the cell cycle, including cell growth, DNA replication, and organelle multiplication and for the proper differentiation of somatic anther cells. Although no major cytological differences were observed between mutant and fertile anthers at this stage, many cell processes already appear to be compromised at the start of PMC maturation. Genes with nucleic acid binding activity are likely essential for $\mathrm{L} / \mathrm{Z}$ transition. We conclude that a switch of cell processes programmed by new gene expression is necessary for subsequent meiotic entry and progression by the PMC and for normal development of somatic cell types.

\section{AM1 affects the transcriptomes of meiocytes and tapetum}

Based on cell counts, the PMCs constitute less than 1\% of anther cells at the 1.0 and $1.5 \mathrm{~mm}$ stages in maize [3]. In transverse sectional area, however, these giant 


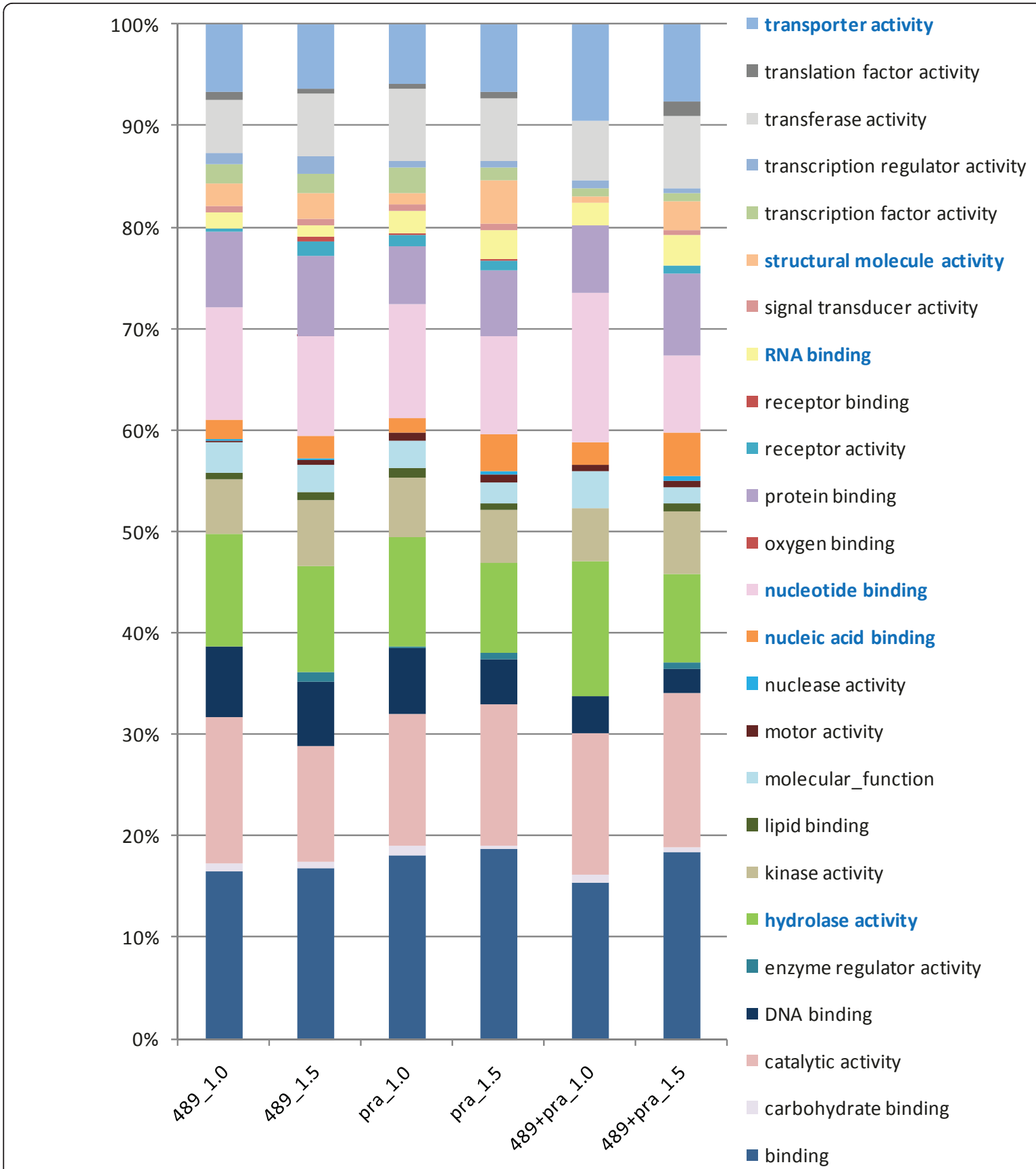

Figure 4 Gene ontology annotation. Percentage of each gene ontology category of differentially expressed transcripts in mutant anthers compared to fertile (excluding unknowns) found in: 489_1.0: $1.0 \mathrm{~mm}$ am1-489; 489_1.5: $1.5 \mathrm{~mm}$ am 1-489; pra_1.0: 1.0 mm am1-pral; pra_1.5: 1.5 mm am1-pral; 489+pra_1.0: both am1-489 and am1-pral at 1.0 mm; 489+pra_1.5: both am1-489 and am1-pral at 1.5 mm. Categories are in alphabetical order, starting from the bottom of the list.

cells comprise $33 \%$ of the locule (Figure 1c) and about $10 \%$ of the anther (data not shown). Using data in Tang et al. 2010 [41] reporting the yield of total RNA from isolated rice PMCs we calculate that rice PMCs contain at least 25 times more RNA than a typical cell; similarly using data in Chen et al. 2010 [42], Arabidopsis PMCs must contain at least 100 times more RNA than typical diploid cells. Therefore in analyzing whole anthers, the expectation would be that $22-53 \%$ of extracted RNA would be derived from the PMC population. As maize is more closely related to rice and anther size and morphology are also more similar, we take a figure of about $20 \%$ as the expected PMC contribution to total RNA. Based on these assumptions, transcripts enriched 4-5 
fold in fertile anthers compared to either am1 mutant are likely to be PMC-enriched or PMC-specific transcripts.

Nonetheless, a substantial fraction of the 4,587 transcriptome changes documented in Figure 3b (with 496 redundant ones removed from the 5,083 total) as specific to either am1-489 or am1-praI compared to their fertile counterparts could occur in somatic tissue surrounding the pre-meiotic cells. Male-sterile mutants with tapetal defects are very common (c.f. [22] references therein) because these nurse cells play critical roles in relaying nutrients and structural components to the PMCs. Although not investigated to date, the absence of proper PMC maturation could readily impact neighboring tapetal cell differentiation over the 1.0 to $1.5 \mathrm{~mm}$ growth period as was hypothesized for the On/ Off class of transcripts. As a first step in assigning transcripts to the pre-germinal or somatic tissues, we cross checked against an independent array data set for laserdissected pools of PMCs or tapetal cells from fertile anthers at $1.5 \mathrm{~mm}$ (T. Kelliher and V. Walbot, unpublished data). PMC-enriched genes were defined as those expressed at least 2 times higher in the PMCs than the surrounding tapetum; conversely, those expressed at least 2-fold higher in the tapetum compared to PMCs constitute the tapetum-enriched class. Of the mis-regulated genes in whole anthers unique to either allele $(\mathrm{N}=$ $4,587), 13 \%(\mathrm{~N}=613)$ were found in the PMC-enriched class; $10 \%(\mathrm{~N}=486)$ were in the tapetum-enriched class. Considering each allele separately, of the 3,174 non-redundant am1-489 specific changes, $10 \%(\mathrm{~N}=$ $325)$ are in the PMC-enriched class and $12 \%(\mathrm{~N}=393)$ are tapetum-enriched. A different proportion is found in am1-praI: of the non-redundant am1-praI specific changes $(\mathrm{N}=1,577), 20 \%(\mathrm{~N}=317)$ are PMC-enriched and $7 \%(\mathrm{~N}=107)$ are tapetum-enriched. We conclude that AM1 has a major impact on tapetal differentiation during PMC maturation, with a higher ratio of tapetal defects in am1-489 than in am1-praI; we hypothesize that the more substantial alterations in tapetal cells in am1-489 ultimately lead to under-developed, shorter am1-489 mutant anthers. We hypothesize that genes found in the combined list of PMC- and tapetalenriched genes are likely to be important for normal growth of other anther cell types. For both am 1 mutant alleles, this class comprises $75 \%$ of the mis-regulated genes indicating that mis-differentiation of the PMCs has a major impact on somatic anther cells.

Among the 530 genes mis-regulated in both mutants, 297 (56\%) detected in whole anthers are in the PMCenriched class while only $1 \%$ are expressed $\sim 2$ times higher in tapetum. AM1 protein was previously detected by immunolocalization only in meiocytes and not in the adjacent tapetal layer in fertile meiotic anthers [10], and the Ameiotic1 transcript intensities detected in the PMCs (early meiosis) are about 4-5 times higher than in the tapetum at $1.5 \mathrm{~mm}$. Therefore, the absence of AM1 or the presence of an aberrant protein has a major impact on PMC gene expression. Sixty-four of the highly PMC-enriched genes are listed in Table 3; at the criterion of 4 fold or higher in meiocytes than tapetum at $1.5 \mathrm{~mm}$ many of these genes could be PMC-specific based on our estimate of the expected contribution of PMC RNA to total anther RNA. Members include $A m 1$, Skp1B, AGO2 [43], and UBA (ubiquitin-associated) genes.

Maize homologs of well known meiotic genes show transcriptional mis-regulation in the am1-mutants (Additional File 7): $S k p 1$, an essential component of the ubiquitin-ligase complex involved in cohesion distribution and nuclear re-organization during leptotene to pachytene stage $[24,26,44]$; $\operatorname{Rad} 54$, a $\operatorname{Rad} 51$ partner involved in chromatin re-modeling and repair of DNA double-strand breaks [28,29,45]; Msh4 and Zip4/Spo22like, required genes for interferent crossing-over formation [27,46]; and Zyp1, the central element of the synaptonemal complex that starts to assemble on chromosome at the $\mathrm{L} / \mathrm{Z}$ transition [47]. We also note the mis-expression of the meiotic cyclin SDS essential for the control of meiotic prophase I progression in Arabidopsis and rice [48].

\section{K-median clustering of PMC-enriched genes}

The 297 PMC-enriched genes differentially expressed in both mutants (Additional File 7) were clustered with algorithms from the Cluster 3.0 program http:// bonsai.hgc.jp/ mdehoon/software/cluster/. K-median clustering based on Euclidean distance, uncovered several interesting clusters, and these are displayed in a heat map (Figure 5). A group of 37 genes were upregulated in am1-praI but down-regulated in am1-489 anthers compared to fertile at $1.5 \mathrm{~mm}$ (Figure 6 and Additional File 8). A subset of these parallel $A m 1$ expression, including genes homologous to Agamouslike MADS-box transcription factor [49], cell cycle associated Mob1-like [50], SPX domain-containing, zinc finger (C3HC4-type RING finger)-related, and Suppressor of Gene Silencing 3 (SGS3) [51,52] homolog (Additional File 9). These genes could have high relevance for meiotic entry or suppression of mitosis. Genes that have similar patterns in both am1-489 and am1-praI could be essential for meiotic prophase I progression. For instance, 45 genes are down-regulated in both mutants and cluster with $S k p 1 B$ and Rad54like (Figure 7 and Additional File 10). Other clusters contain genes with defined meiosis-related functions include Mmd1, Zyp1, Apospory, and Werner syndrome ATP-dependent helicase gene families [53-56]. 
Table 3 List of $L / Z$ transition genes

\begin{tabular}{|c|c|c|}
\hline Maize Est & Maize Gene ID & Description \\
\hline Al692111 & AC198518.3_FG002 & Sterile alpha motif domain family protein \\
\hline AW231811 & GRMZM2G033236 & ND \\
\hline BM378145 & GRMZM2G041418 & Putative NADH dehydrogenase \\
\hline BM500607 & GRMZM2G007736 & Alpha-trehalose-phosphate synthase (UDP-forming) \\
\hline CB280793 & GRMZM2G029385 & Mitochondrial import inner membrane translocase subunit \\
\hline CD436448 & GRMZM2G342807 & Unknown protein \\
\hline CF059625 & GRMZM2G149347 & Nucleic acid binding zinc finger $\mathrm{CCCH}$ type \\
\hline CF626131 & GRMZM2G454838/GRMZM2G328795 & ZIP4/SPO22-LIKE \\
\hline CN844996 & GRMZM2G149392 & Unknown protein \\
\hline DQ663482 & GRMZM5G883855 & Ameiotic1 \\
\hline DR830496 & GRMZM2G113631 & ND \\
\hline DT946613 & GRMZM2G310739 & Glucan endo-1,3-beta-glucosidase 5 \\
\hline TC279480 & GRMZM2G041328 & Histone-arginine methyltransferase CARM1 \\
\hline TC279550 & GRMZM2G146206 & Triosephosphate isomerase, cytosolic \\
\hline TC280195 & GRMZM2G134708 & Pyridine nucleotide-disulphide oxidoreductase \\
\hline TC281079 & GRMZM2G027173 & Phagocytosis and cell motility ELMO domain-containing protein 2 \\
\hline TC282924 & GRMZM2G107495 & Unknown protein \\
\hline TC283097 & GRMZM2G050684 & CBS (cystathionine beta-synthase) domain containing protein \\
\hline TC284163 & GRMZM2G347717 & UDP-glucuronic acid decarboxylase \\
\hline TC284639 & GRMZM2G122965 & Unknown protein \\
\hline TC286486 & GRMZM2G071630 & Cytosolic glyceroldehyde-3-phosphate dehydrogenase GAPC3 \\
\hline TC287318 & GRMZM2G028369 & Chorismate mutase type ॥ \\
\hline TC287640 & GRMZM2G139941 & ND \\
\hline TC287858 & GRMZM2G360681 & Heat-shock protein 101 \\
\hline TC288590 & GRMZM2G097135 & BAG domain containing protein (BCL-2-ASSOCIATED ATHANOGENE 5) \\
\hline TC289172 & GRMZM2G047372 & Unknown protein \\
\hline TC289341 & GRMZM2G116243 & Calcineurin B subunit-related \\
\hline TC289354 & GRMZM2G052474 & Similar to NC domain-containing protein-related \\
\hline TC289458 & Unannotated & ND \\
\hline TC289461 & GRMZM2G140994 & Rhomboid domain containing 1 \\
\hline TC289712 & GRMZM2G071739 & Ubiquitin-associated (UBA)/TS-N domain-containing protein \\
\hline TC289753 & GRMZM5G878823 & Putative RNA-binding protein RNP-D precursor \\
\hline TC290471 & GRMZM2G109496 & Probable protein phosphatase $2 \mathrm{C}$ \\
\hline TC291009 & GRMZM2G032562 & SKP1-like protein 1B \\
\hline TC295884 & GRMZM2G148872 & SOUL heme-binding protein \\
\hline TC296255 & GRMZM2G080930 & Putative RSZp22 splicing factor \\
\hline TC296845 & GRMZM2G067350 & 4/1 protein \\
\hline TC297030 & GRMZM2G020766 & Pseudogene of a potassium transporter \\
\hline TC298798 & GRMZM5G889299 & Unknown protein \\
\hline TC301446 & GRMZM2G045970 & Cytidylyltransferase family protein \\
\hline TC301790 & GRMZM2G354827 & Benzothiadiazole-induced somatic embryogenesis receptor kinase 1 (SERK1) \\
\hline TC302695 & GRMZM2G017388 & Cation/calcium exchanger 4 \\
\hline TC303479 & GRMZM2G007791 & Argonaute protein, similar to AGO2 \\
\hline TC303749 & GRMZM2G020766 & Pseudogene of a potassium transporter \\
\hline TC304331 & GRMZM2G457370 & AGO1 \\
\hline TC305157 & GRMZM2G159724 & NADP-dependent malic enzyme \\
\hline TC305158 & GRMZM2G159724 & NADP-dependent malic enzyme \\
\hline TC305266 & GRMZM2G007300 & Ubiquitin-conjugating enzyme E2 UBC7 \\
\hline TC305399 & GRMZM2G050329 & SPX (SYG1/Pho81/XPR1) domain-containing protein \\
\hline TC305717 & GRMZM5G801875 & MATE efflux family protein \\
\hline TC306072 & GRMZM2G179215 & ND \\
\hline
\end{tabular}


Table 3 List of L/Z transition genes (Continued)

\begin{tabular}{lll}
\hline TC306331 & GRMZM2G349996 & ND \\
TC307437 & GRMZM5G832378 & ND \\
TC308672 & Unannotated & ND \\
TC309747 & Unannotated & ND \\
TC309993 & GRMZM2G001803 & ND \\
TC310318 & GRMZM2G306679 & 17.4 kDa class I heat shock protein 3 \\
TC310688 & GRMZM2G178960 & Ribulose-phosphate 3-epimerase \\
TC310843 & GRMZM2G170927 & Vacuolar proton pyrophosphatase \\
TC312974 & GRMZM2G351810 & Unknown protein \\
TC314126 & GRMZM2G043992 & Unknown protein \\
TC314427 & GRMZM2G125775 & AN17; zinc finger (AN1-like)-like protein \\
TC314676 & GRMZM2G119523 & Unknown protein \\
\hline
\end{tabular}

These are genes affected in anthers with either mutant allele compared to fertile anthers at $1.5 \mathrm{~mm}$ and are predominantly expressed (four times or higher) in PMCs than in tapetum at $1.5 \mathrm{~mm}$.

Items in bold are known genes previously reported to be associated with meiosis or meiosis-related processes; ND: not determined.

\section{Discussion}

Meiotically competent cells in plants differentiate late in floral ontogeny. Presently, the steps required for specification of meiotic competence in a tiny number of floral somatic cells are unknown. However, nuclear events in meiotic cells are readily distinguishable from those in mitotic cells, and the developmental program of archesporial cells and PMCs is independent of successful somatic cell development at least through progression into prophase I [2]. The ameiotic1 mutants of maize demonstrate that conducting meiosis is distinguishable from the preceding PMC differentiation events such as cell and nuclear enlargement and a rounded cell shape. In all am1 mutant anthers, archesporial cells are normal and proliferate to make the normal numbers and morphology of highly enlarged PMCs present in $1.0 \mathrm{~mm}$ maize anthers; somatic cell differentiation is also cytologically normal. For all am1 alleles except am1-praI, the PMCs remain mitotic rather than switching to meiosis, suggesting that both repression of mitosis and activation or maintenance of meiotic programs could be required to enter meiosis and that AM1 contributes to these processes. Cells in the somatic layers are still dividing at 1.0 $\mathrm{mm}$ but most layers have stopped dividing by $1.5 \mathrm{~mm}$ [3]; the somatic cessation of mitosis does not require AM1.

Global transcriptome analysis reinforces distinctions in the anatomical phenotypes of am1-489 and am1-praI. Both mutants have few cytological and moderate transcriptome differences compared to fertile at $1.0 \mathrm{~mm}$. At $1.5 \mathrm{~mm}$ fertile PMCs have entered meiosis while mutant PMCs have not; unsynchronized mitosis is observed in am1-489 PMCs, and these cells in am1-praI are still at the pre-meiotic interphase. The mutant transcriptomes are more distinctive compared to fertile anthers at 1.5 $\mathrm{mm}$. A comparison of the am1-praI profiles at 1.0 and
$1.5 \mathrm{~mm}$ confirms that these anthers are developmentally delayed at $1.0 \mathrm{~mm}$ and that a substantial fraction of the transcriptome expected at $1.0 \mathrm{~mm}$ appears later at 1.5 $\mathrm{mm}$. These results indicate that AM1 has an early impact on the pace of PMC maturation that is critical for timely meiotic entry.

From profiling we discovered maize genes associated with meiotic entry and the $\mathrm{L} / \mathrm{Z}$ transition in PMCs using three methods: analysis of meiosis-associated genes, K-median clustering, and comparison to transcripts detected in isolated normal PMCs. Many meiosis-associated transcript types identified in our transcriptome profiling study have been reported to play major roles in sister chromatid cohesion, synapsis, homologous recombination, and double-strand repair [57]. Based on homology to defined proteins, a region shared between SWI1/DYAD1 and AM1 is predicted to have DNA binding ability like other PHD finger homeodomain proteins [10] and likely to be involved in regulating transcription. Our array data clearly demonstrate that AM1 attenuates the expression of other meiotic genes. Interestingly, none of the meiosis-associated genes are regulated in an absolute On/Off pattern, somewhat surprising given that am1-489 PMCs perform mitosis instead of meiosis. These results redefine a role of AM1 in the modulation of transcript accumulation for many critical meiotic genes rather than simply switching them on or off. This could also imply that many meiotic genes including those associated with DNA repair are expressed whether or not meiosis will proceed; this distinguishes plants from other well-studied eukaryotes.

One critical step to distinguish meiosis from mitosis is homologous chromosome pairing. Only during meiosis are homologous chromosomes held together by the formation of the synaptonemal complex and remain 


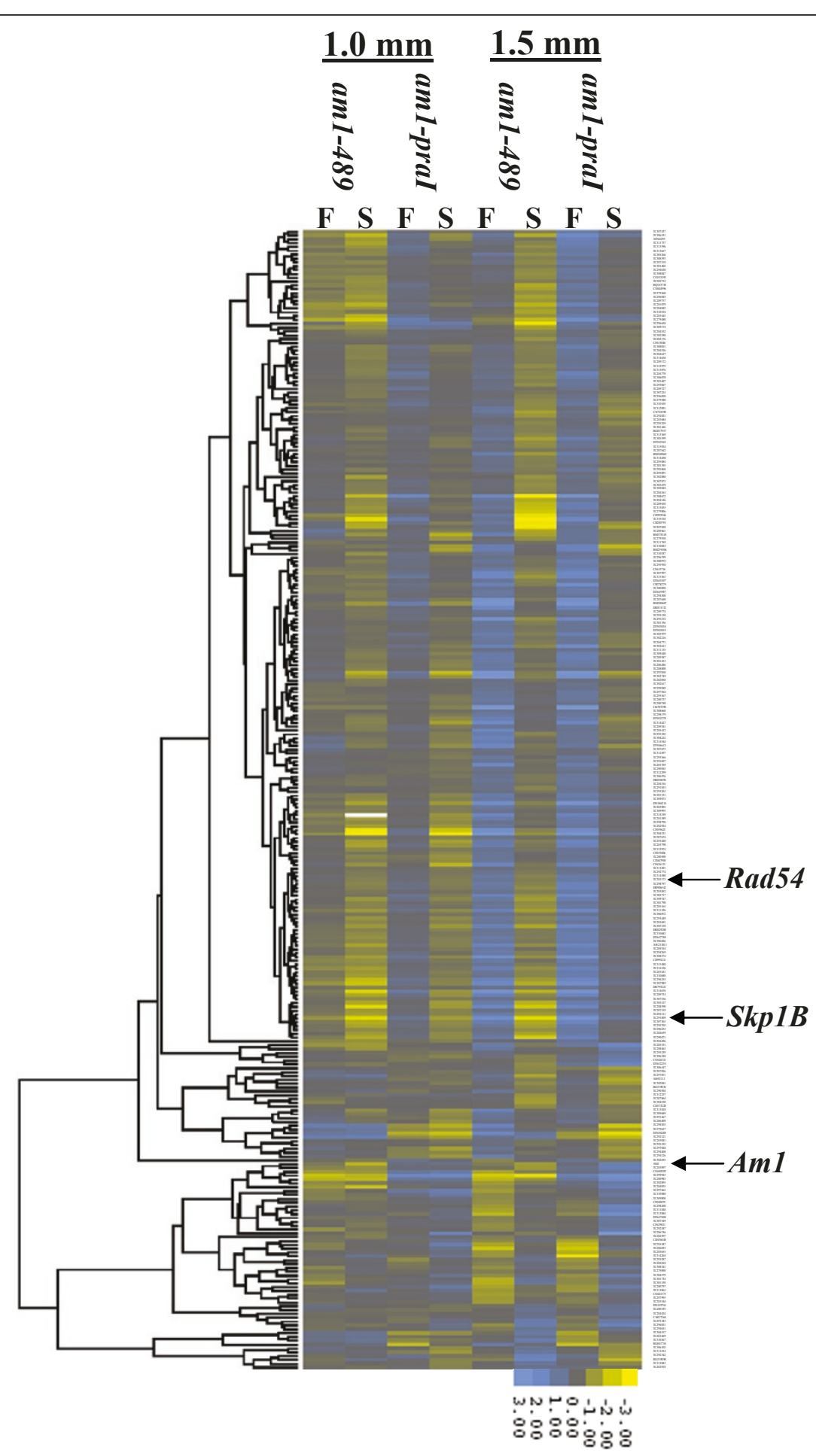

Figure 5 Heat map of 297 PMC-enriched, differentially expressed genes in mutant (S) versus fertile (F) anthers.

attached until meiosis prophase I has completed by the formation of chiasmata, the cytological manifestation of crossovers. Extensive studies have identified numerous genes involved in these processes after meiotic entry
[58], and several genes highlighted in comparing am1 to fertile are in this category (Additional File 2). Transcript types affected only in am1-489 include those with homology to Afd1, RPA70, Ms5, and Msh5 gene families. 


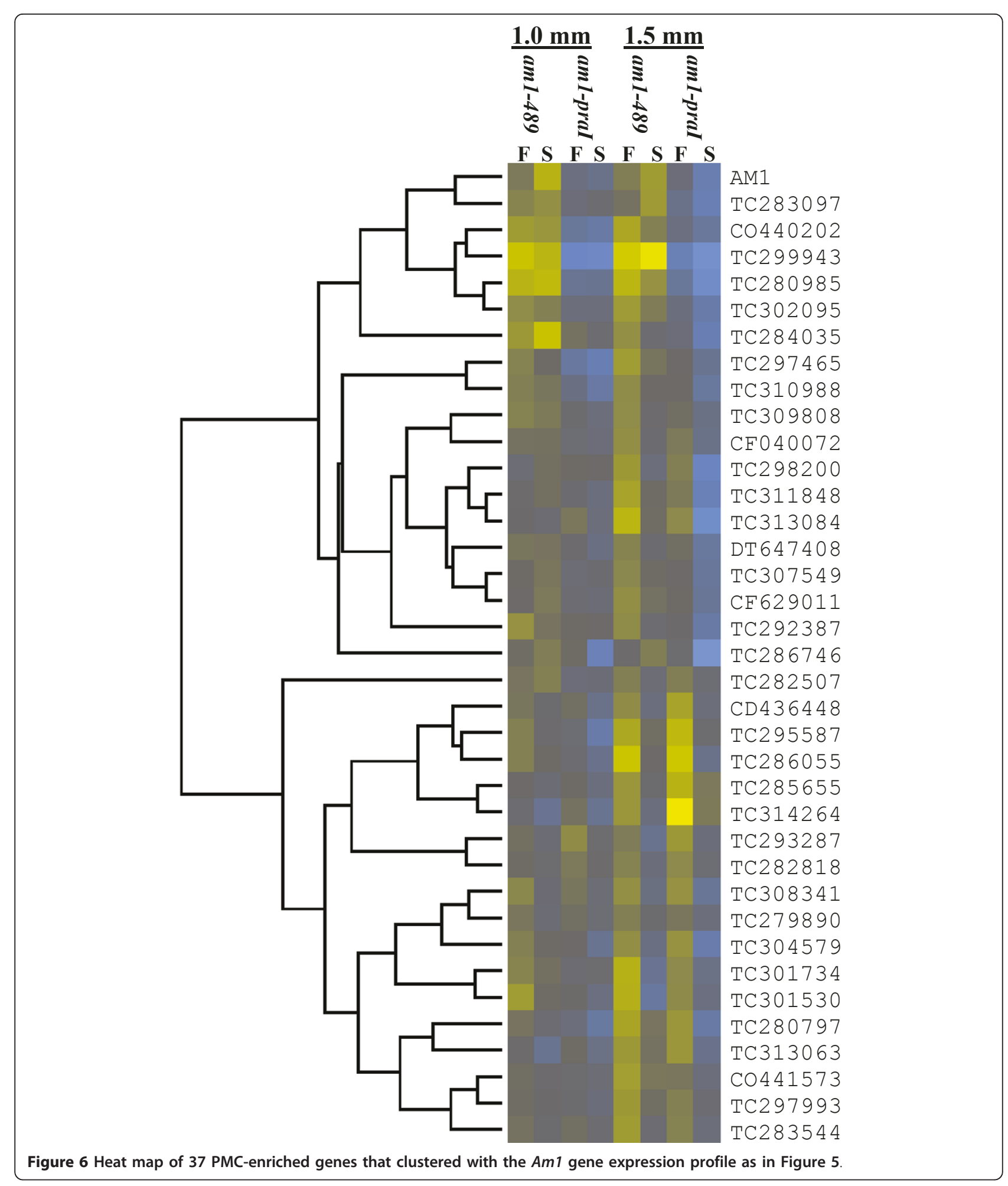

Transcript differences found in both mutant anthers include those with homology to Skp1B, Rad54-like, $M s h 4, S d s$, and Zyp1. AFD1, a maize REC8 homolog acting downstream of ASY1/HOP1, is associated with the maintenance of the axial/lateral elements of the synaptonemal complex and regulation of sister chromatid cohesion [33]. Pawlowski et al. [10] found that AFD1 is loaded onto the chromatin in am1-praI but not in 


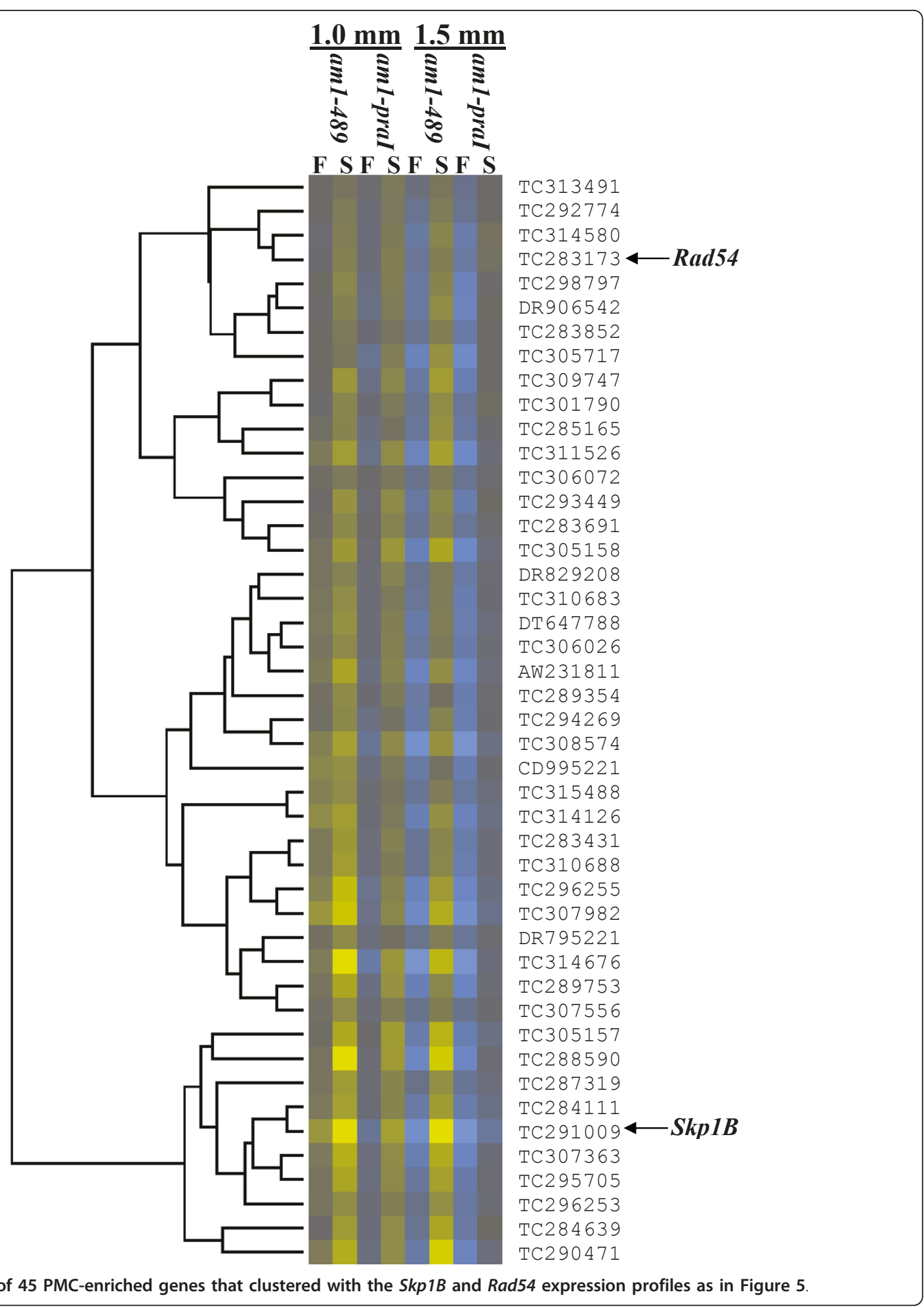

am1-1 PMCs. Both the array and qRT data showed a moderate yet significant reduction of $A f d 1$ transcripts at $1.0 \mathrm{~mm}$ in am1-489, which is phenotypically similar to am1-1, but not in am1-praI. Dmc1, a RecA homolog, is involved in meiotic double strand DNA break repair [59]. In plants Dmc1 transcripts are found in PMCs and ovule meiotic cells [60] and sporadically in mitotic cells [61]. The maize Dmc1 homolog analyzed is down- 
regulated in am1-489 but not in am1-praI compared to fertile. Thus the single amino acid mutation in the am1praI protein does not impact the transcript levels of $D m c 1$ or $A f d 1$ genes. We can conclude that an important transcriptional regulation of $A f d 1$ and $D m c 1$ occurs during meiotic entry but is not essential later during the $\mathrm{L} / \mathrm{Z}$ transition. The status of the praI "meiocytes" is probably affected by another level of control for achieving a zygotene-like stage. Other mechanisms such as post-transcriptional regulation and/or nuclear entry of specific meiotic proteins might then be more important for meiotic prophase progression [62].

RAD51, another $\operatorname{Rec} A$ homolog, is required for homology searching, chromosome pairing, DNA strand transfer (D-loop formation), and double-strand break repair in meiosis and in DNA repair in somatic cells [63]. RAD51 protein is absent in am1 mutants [10]. Neither Rad51A nor Rad51A2 transcript levels are affected, therefore, post-transcriptional regulation of RAD51 protein levels is likely. RAD54 is a branch migration protein that is involved in dissociating D-loops formed by DMC1 during meiosis as well as D-loops formed by RAD51 though less efficiently [45]. Interestingly, Rad54like transcript is significantly reduced in both $a m 1$ mutants.

Skp1B of another known meiotic gene family is also down-regulated in both am1 mutants. The Arabidopsis Skp1-like1 (ASK1) gene was previously reported to perform a critical role in recombination during the leptotene to pachytene stages $[24,25]$. ASK1 protein is important for many cell processes including modifying and reconstructing meiotic chromatin [24,25] and telomere formation [26]. Telomere bouquets are missing in am1-489 and are retarded or incomplete in am1-praI [10]. Telomere clustering on the nuclear envelope is another crucial event of meiotic chromosome organization during prophase I that occurs at the $\mathrm{L} / \mathrm{Z}$ transition in many organisms $[64,65]$. Based on clustering analysis, Rad54-like and $S k p 1 B$ expression patterns are very similar and dependent on $A m 1$. Therefore, all three proteins might work in concert to advance meiocytes through the L/Z transition, the stage when am1-praI is arrested.

Other interesting genes differentially expressed in both mutants compared to fertile that have been implicated in the meiotic process include Always Early1 [66], Werner syndrome helicase [56], Zap-3 telomerase [67], and kinesin [68]. Our analysis of these genes along with Skp1B, Rad54-like and $A m 1$ shows a predominant expression in meiocytes (at least 5 times higher than whole anthers and at least 3 times higher than tapetum). This finding suggests that AM1 interacts directly or indirectly with these proteins in establishing or stabilizing meiotic chromosomes. Two good candidate genes for apomixis, Afd1 and Brassinosteroid insensitive1- associated receptor kinase genes $[69,70]$, were downregulated in am1-489 anthers at $1.0 \mathrm{~mm}$ and in both mutant anthers at $1.5 \mathrm{~mm}$, respectively.

According to Palmer [9], am1-1 anthers degenerate after one or 2 rounds of ectopic PMC mitosis and fail by the $\sim 2.2 \mathrm{~mm}$ anther stage. am1-489 anthers also cease growth, and this is similar to most other premeiotic male-sterile mutants [22]. Therefore, the continued growth of am1-praI anthers to 4-5 $\mathrm{mm}$ and their normal morphology indicate that the transcriptome differences are primarily causing defects in the PMCs and not significantly impairing somatic cell layers, despite inferred changes in the somatic and detected changes in the tapetal transcriptomes. We further conclude that meiotic entry by PMCs is sufficient to trigger somatic anther growth; the nature of the developmental signal is yet to be determined.

To more critically address the cell type specificity of transcriptome alterations, the 530 non-redundant genes differentially expressed in both $a m 1$ alleles were used to query gene lists derived from array profiling of laser microdissection-enriched PMCs or tapetal cells in normal anthers. Fifty-six percent were expressed at least 2fold higher in PMCs compared to those found in the immediately adjacent tapetum. Our results indicate that either the complete absence of AM1 or the presence of excess aberrant AM1-PRAI protein has a profound impact on gene expression in the PMCs during the maturation phase from 1.0 to $1.5 \mathrm{~mm}$ anther length, including the period of meiotic entry up to the $\mathrm{L} / \mathrm{Z}$ transition stage. Based on estimation of the contribution of PMC RNA to total anther RNA [41], we hypothesize that transcripts enriched 4-fold or higher could be PMC-specific. In fact, the highest enrichment observed was 9-fold, initially puzzling because PMCs are less than $1 \%$ of the cell population but should contain many unique transcripts associated with meiosis. After accounting for RNA contribution, however, enrichment of 4- to 5-fold in isolated PMC is the expectation.

Recently, multiple microarray or RNA-Seq analyses of purified meiocytes have been reported $[5,41,42,71]$. Using manual methods or laser capture microdissection, meiocytes relatively free of contaminating somatic cells were obtained in sufficient numbers for analysis. The limitation of these rice and Arabidopsis analyses was that all stages of meiosis were represented; even if there is little or no de novo transcription during meiosis, transcripts present initially in PMCs may have decayed during meiosis, and the mixed meiocyte population is hence not ideal for analysis. In these studies from 800 to 1,586 meiocyte-specific transcript types were identified. For maize, we used whole anther analysis and comparison to an independent dataset of laser microdissected PMCs and tapetal cells in carefully 
staged $1.5 \mathrm{~mm}$ fertile anthers at prophase I, and we also used the comparison of am1-489 and am1-praI to discover meiosis-associated genes. Prophase I spans only one day of the 30 days in maize anther development. From our analysis, 297 PMC-enriched genes were identified as mis-regulated by both mutants within the narrow window of prophase I. Additionally, we identified genes mis-regulated at the start of PMC maturation, particularly in the am1-489 mutant, that are likely associated with the suppression of mitosis and early preparation for meiosis.

Our am 1 transcriptome data can serve as a resource to decipher the complex networks of meiosis initiation in plants. Comparing results from the two am 1 alleles provides insights into multiple control points.

\section{Conclusion}

Transcriptome changes in $a m 1$ anthers prior to meiosis lead to loss of meiotic competence in the PMCs. Transcript types affected only in am1-489 anthers and resembling the $A m 1$ expression pattern likely define requirements for suppression of mitosis and entry into meiosis and ultimately influence the development and maturation of anther somatic layers; meiosis-associated processes affected in am1-489 mutants include genes important for sister chromatid cohesion, and RNA interference. Transcripts differentially regulated in both mutants are more likely related to progression through the $\mathrm{L} / \mathrm{Z}$ transition. This microarray analysis indicates that maize meiotic prophase is controlled at multiple levels and that AM1 controls the RNA level of only a subset of meiotic genes at the critical steps of meiotic entry and the $L / Z$ transition.

\section{Methods}

\section{Plant materials}

Two maize (Zea mays L.) stocks with different hybrid backgrounds containing the am1-489 (50\% B73 + 25\% A $619+25 \%$ mixed other or unknown) or am1-praI allele (75\% A619 + 25\% mixed other or unknown) were propagated by male-sterile $(a m 1 / / a m 1) \times$ fertile sibling $(a m 1 / / A m 1)$ crosses or self-pollination of fertile heterozygotes $(a m 1 / / A m 1)$. Immature tassel branches were carefully removed from 4-6 week old plants and kept moist in wet paper towels until dissection. Anthers were recovered from upper florets with two pairs of sharp forceps, measured with a micrometer, and collected directly into screw-cap microcentrifuge tubes chilled in liquid nitrogen. Sixty $1.0 \mathrm{~mm}$ and thirty $1.5 \mathrm{~mm}$ anthers were collected for each biological replicate. For cytological staging, the anther locule contents were expelled onto a microscope slide using dissecting needles. Standard acetocarmine staining [72] was performed, and samples were observed at $400 \times$ with an oil lens to classify meiotic stages or confirm mitotic chromosomes.

\section{Microarray experiment}

Total RNA was extracted using the TRIzol ${ }^{\circledR}$ Plus RNA Purification Kit (Invitrogen, Carlsbad, CA) from each anther pool. RNA quality and quantity were examined on a Bioanalyzer ${ }^{\circledR}$ (Agilent, Santa Clara, CA). Amplification and balanced dye-labeling of four biological replicates were performed according to manufacturer's recommendation. Three technical replicates for each sterile biological pool (12 hybridizations) and one technical replicate for each fertile biological (4 hybridizations) were performed. After hybridization on a customized maize $4 \times 44 \mathrm{~K}$ array (Agilent ID 16047, original probe design as described in [20], the slides were washed, dried, and scanned on Agilent's High Resolution Microarray Scanner; data were processed with Feature Extraction Software. The resulting median foreground values for the red and green channels were normalized in two steps using the limma package [73] in R: "within arrays" using the lowess method and "Between arrays" using the quartile method. Probes with expression values greater than 3.0 standard deviations above the average foreground of the array's negative controls were considered "on", resulting in an estimated false discovery rate of $0.13 \%$. However, probes with fewer than $75 \%$ of the replicate measurements scored as "On" were then excluded from further analysis. Significance for differential expression was set at $\sim 1.5$-fold $(\log 2 \sim 0.58)$ with a p-value $\leq 0.05$. Microarray data for these experiments are available online at GEO http:// www.ncbi.nlm.nih.gov/geo/ under accession number GSE30149.

\section{Quantitative RT-PCR (qRT)}

Transcript abundances were quantified from three biological replicates for each sample type and four technical replicates for each sample (12 RT reactions for each gene in each type of sample). First-strand cDNA was synthesized from $1 \mu \mathrm{g}$ total RNA using Superscript III ${ }^{\mathbb{R}}$ reverse transcriptase (Invitrogen). Diluted cDNA was amplified in a $20 \mu \mathrm{l}$ qRT reaction containing $10 \mu \mathrm{l}$ of $\mathrm{iQ}$ SYBR Green Supermix (Bio-Rad, Hercules, CA) and 250 $\mathrm{nM}$ of each primer on an Opticon $2^{\circledR}$ system (Bio-Rad). The cyanase gene was used as the constitutive internal standard [74]. Primer sequences and product sizes for the genes surveyed in qRT are listed in Additional File 11. The amplification protocol was $95^{\circ} \mathrm{C}$ for $5 \mathrm{~min}$ followed by 40 cycles of $95^{\circ} \mathrm{C}$ for $10 \mathrm{sec}, 60^{\circ} \mathrm{C}$ for $30 \mathrm{sec}$, and plate read. Melting curve analysis was performed every $0.5^{\circ} \mathrm{C}$ from 55 to $95^{\circ} \mathrm{C}$ with a $10 \mathrm{sec}$ hold at each step to check for production of a single amplicon. The 
cycle threshold $(\mathrm{Ct})$ value and amplification efficiency were determined using PCR Miner version 2 [75].

\section{Additional material}

Additional file 1: Ordered $K$-median $(K=4)$ hierarchy linkage tree of global transcriptome data among 8 biological sample types: male sterile (S) and fertile (F) am 1-489 (489) and am1-pral (pra) anthers at 1.0 and $1.5 \mathrm{~mm}$ stages. Coph (cophenetic correlation) = 0.9842

Additional file 2: Heat map of 78 probes spanning 45 meiotic genes on the Agilent $4 \times 44 \mathrm{~K}$ array. $\mathrm{F}=$ fertile; $\mathrm{S}=$ male sterile; $\mathrm{ND}=$ not determined.

Additional file 3: Congruence between the pilot array $(P)$ and the reported array (M) studies. A chart (a) showing average intensities as listed in (b) of 297 differentially expressed, PMC-enriched genes from the two independent studies. 489S: male sterile am 1-489; praS: male sterile am 1-pral; 1.0: $1.0 \mathrm{~mm}$ anthers; $1.5: 1.5 \mathrm{~mm}$ anthers. B.

Additional file 4: Quantitative RT-PCR (qRT) validation of the levels of $A m 1$ and 10 other meiotic genes in anthers: male sterile (S) and fertile (F) am 1-489 (489) and am 1-pral (pra) anthers at 1.0 and 1.5 $\mathrm{mm}$ stages. Standard deviations are indicated for the qRT results.

Additional file 5: Western analysis of total proteins extracted from tassel branches containing anthers ranging from 1.0 to $3.0 \mathrm{~mm}$ in length, collected from homozygous am 1-489 mutant (am1-489), homozygous am 1-pral mutant (am1-pral), and wild type (WT) plants. Polyclonal antibodies raised to the AM1 protein and specific to actin (control) are described in Pawlowski et al. (10).

Additional file 6: Gene counts of GO-annotated transcripts of: total detected transcripts (all); differentially expressed in am 1-489 and am1-pral anthers compared to common fertile dataset at $1.0 \mathrm{~mm}$ (489_1.0, pra_1.0) and $1.5 \mathrm{~mm}$ (489_1.5, pra_1.5), respectively; differentially expressed in both mutants compared to fertile at 1.0 $\mathrm{mm}$ (489+pra_1.0) and $1.5 \mathrm{~mm}$ (489+pra_1.5).

Additional file 7: List of 297 PMC-enriched genes differentially expressed in both am1-489 and am1-pral mutants.

Additional file 8: List of 37 PMC-enriched genes clustered with the Am1 transcript expression pattern as in Figure 6. Highlighted items are genes previously reported to be associated with meiosis or meiosisrelated processes; ND: not determined.

Additional file 9: Heat map and annotation of the six transcripts most similarly regulated with the Ameiotic 1 gene. $F=$ fertile; $S=$ male sterile; $N D=$ not determined.

Additional file 10: List of 45 PMC-enriched genes clustered with the Skp1B transcript expression pattern as in Figure 7. Highlighted items are genes previously reported to be associated with meiosis or meiosisrelated processes. ND: not determined.

Additional file 11: Primer sequences and RT product sizes of all genes surveyed in qRT validation experiments.

\section{List of abbreviations}

Am1: Ameiotic1; L2-d: derived from the L2 layer; L/Z: leptotene/zygotene; PMCs: pollen mother cells; qRT: quantitative RT-PCR.

\section{Acknowledgements}

We would like to thank Darren Morrow for technical advice on the microarray experiments. This research was supported by the National Science Foundation (07-01880).

\section{Author details}

'Department of Biology, Stanford University, Stanford, CA 94305, USA 2Department of Molecular and Cell Biology, University of California, Berkeley, CA 94720, USA. ${ }^{3}$ Institute of Plant and Microbial Biology (IPMB), Academia Sinica, Taipei, 11529, Taiwan.

\section{Authors' contributions}

GN designed and carried out the microarray experiments, performed qRT validation, analyzed the data, and wrote the initial draft of the manuscript. AR annotated the data and wrote sections of the manuscript. RCW helped in the design and carried out the cytological staging, and performed the Western analysis. JFF performed the statistical analysis. WZC and WW conceived of the study, participated in its design and coordination, and helped to edit the manuscript. All authors read, edited, and approved the final manuscript.

\section{Competing interests}

The authors declare that they have no competing interests.

Received: 24 May 2011 Accepted: 26 August 2011

Published: 26 August 2011

\section{References}

1. Pawlowski WP, Sheehan MJ, Ronceret A: In the beginning: The initiation of meiosis. Bioessays 2007, 29:511-514.

2. Sheridan WF, Avalkina NA, Shamrov II, Batyea TB, Golubovskaya IN: The mac1 gene: controlling the commitment to the meiotic pathway in maize. Genetics 1996, 142:1009-1029.

3. Kelliher $\mathrm{T}$, Walbot $\mathrm{V}$ : Emergence and patterning of the five cell types of the Zea mays anther locule. Dev Biol 2011, 350:32-49.

4. Hamant $\mathrm{O}, \mathrm{Ma} \mathrm{H}$, Cande WZ: Genetics of meiotic prophase I in plants. Annu Rev Plant Biol 2006, 57:267-302.

5. Yang H, Lu P, Wang Y, Ma H: The transcriptome landscape of Arabidopsis male meiocytes from high-throughput sequencing: the complexity and evolution of the meiotic process. Plant J 2011, 65:503-516.

6. Grell RF, Oakberg EF, Generoso EE: Synaptonemal complexes at premeiotic interphase in the mouse spermatocyte. Proc Natl Acad Sci USA 1980, 77:6720-6723.

7. Takegami MH, Yoshioka M, Tanaka I, Ito M: Characteristics of isolated microsporocytes from Liliaceous plants for studies of the meiotic cell cycle in vitro 1981. Plant Cell Physiol 1981, 22:1-10

8. Nonomura K, Eiguchi M, Nakano M, Takashima K, Komeda N, Fukuchi S, Miyazaki S, Miyao A, Hirochika H, Kurata N: A novel RNA-recognition-motif protein is required for premeiotic $\mathrm{G} 1 / \mathrm{S}$-phase transition in rice (Oryza sativa L.). PLoS Genet 2011, 7:e1001265.

9. Palmer RG: Cytological studies of Ameiotic1 and normal maize with reference to premeiotic pairing. Chromosoma 1971, 35:233-246.

10. Pawlowski WP, Wang CJR, Golubovskaya IN, Szymaniak JM, Shi L, Hamant O, Zhu T, Harper L, Sheridan WF, Cande WZ: Maize Ameiotic1 is essential for multiple early meiotic processes and likely required for the initiation of meiosis. Proc Natl Acad Sci USA 2009, 106:3603-3608.

11. Che L, Tang D, Wang K, Wang M, Zhu K, Yu H, Gu M, Cheng Z: OsAM1 is required for leptotene-zygotene transition in rice. Cell Res 2011, 21:654-665.

12. Mercier R, Armstrong SJ, Horlow C, Jackson NP, Makaroff CA, Veson D, Pelletier $\mathrm{G}$, Jones GH, Franklin FCH: The meiotic protein SWI1 is required for axial element formation and recombination initiation in Arabidopsis. Dev 2003, 130:3309-3318.

13. Agashe B, Prasad CK, Siddiqi I: Identification and analysis of DYAD: a gene for meiotic chromosome organization and female meiotic progression in Arabidopsis. Dev 2002, 129:3935-3943.

14. Golubovskaya I, Grebennikova ZK, Avalkina NA, Sheridan WF: The role of the ameiotic1 gene in the initiation of meiosis and in subsequent meiotic events in maize. Genetics 1993, 135:151-1166.

15. Golubovskaya I, Avalkina N, Sheridan WF: New insights into the role of the maize ameiotic1 locus. Genetics 1997, 147:1339-1350

16. Zickler $\mathrm{D}$, Kleckner $\mathrm{N}$ : The leptotene-zygotene transition of meiosis. Annu Rev Genet 1998, 32:619-697.

17. Mercier R, Veson D, Bullier E, Motamayor JC, Sellier A, Lefevre F, Pelletier G, Horlow C: SWITCH1 (SW1): a novel protein required for the establishment of sister chromatid cohesion and for bivalent formation at meiosis. Genes Dev 2001, 15:1859-1871.

18. Boateng KA, Yang X, Dong F, Owen HA, Makaroff CA: SWI1 is required for meiotic chromosome remodeling events. Mol Plant 2008, 1:620-633.

19. Ravi M, Marimuthu MPA, Siddiqi I: Gamete formation without meiosis in Arabidopsis. Nature 2008, 451:1121-1125. 
20. Ma J, Skibbe DS, Fernandes J, Walbot V: Male reproductive development: gene expression profiling of maize anther and pollen ontogeny. Genome Biol 2008, 9:R181.

21. Skibbe DS, Fernandes JF, Medzihradszky KF, Burlingame AL, Walbot V: Mutator transposon activity reprograms the transcriptomes and proteomes of developing maize anthers. Plant J 2009, 59:622-633.

22. Wang D, Oses-Prieto JA, Li KH, Fernandes JF, Burlingame AL, Walbot V: The male sterile 8 mutant of maize disrupts the temporal progression of the transcriptome and results in the mis-regulation of metabolic functions. Plant J 2010, 63:939-951.

23. Springer NM, Ying K, Fu Y, Ji T, Yeh CT, Jia Y, Wu W, Richmond T, Kitzman J, Rosenbaum H, Iniguez AL, Barbazuk WB, Jeddeloh JA, Nettleton D, Schnable PS: Maize inbreds exhibit high levels of copy number variation (CNV) and presence/absence variation (PAV) in genome content. PLoS Genet 2009, 5:e1000734.

24. Wang Y, Yang M: The Arabidopsis SKP1-LIKE1 (ASK1) protein acts predominately from leptotene to pachytene and represses homologous recombination in male meiosis. Planta 2006, 223:613-617.

25. Yang X, Timofejeva L, Ma H, Makaroff CA: The Arabidopsis SKP1 homolog ASK1 controls meiotic chromosome remodeling and release of chromatin from the nuclear membrane and nucleolus. J Cell Sci 2006, 119:3754-3763

26. Zhao D, Yang X, Quan L, Timofejiva L, Rigel NW, Ma H, Makaroff CA: ASK1 a SKP1 homolog, is required for nuclear reorganization, presynaptic homolog juxtaposition and the proper distribution of cohesin during meiosis in Arabidopsis. Plant Mol Biol 2006, 62:99-110.

27. Chelysheva L, Gendrot G, Vexon D, Doutriaux M-P, Mercier R, Grelon M: Zip4/Spo22 is required for class I CO formation but not for synapsis completion in Arabidopsis thaliana. PLoS Genet 2007, 3:e83.

28. Jaco I, Munoz P, Goytisolo F, Wesoly J, Bailey S, Taccioli G, Blasco MA: Role of mammalian Rad54 in telomere length maintenance. Mol Cell Biol 2003 23:5572-5580.

29. Alexeev A, Mazin A, Kowalczykowski SC: Rad54 protein possesses chromatin-remodeling activity stimulated by the Rad51-ssDNA nucleoprotein filament. Nat Struct Mol Biol 2003, 10:182-186.

30. Magnard J-L, Yang M, Chen YS, Leary M, McCormick S: The Arabidopsis gene Tardy Asynchronous Meiosis is required for the normal pace and synchrony of cell division during male meiosis. Plant Physiol 2010, 127:1157-1166

31. Wang Y, Jha AK, Chen R, Doonan JH, Yang M: Polyploidy-associated genomic instability in Arabidopsis thaliana. Genesis 2010, 48:254-263.

32. Azumi Y, Liu D, Zhao D, Li W, Wang G, Hu Y, Ma H: Homolog interaction during meiotic prophase $I$ in Arabidopsis requires the SOLO DANCERS gene encoding a novel cyclin-like protein. EMBO J 2002, 21:3081-3095.

33. Golubovskaya IN, Hamant O, Timofejeva L, Wang CJ, Braun D, Meeley R, Cande WZ: Alleles of afd1 dissect REC8 functions during meiotic prophase I. J Cell Sci 2006, 119:3306-3315.

34. Ishiguro K, Kim J, Fujiyama-Nakamura S, Kato S, Watanabe Y: A new meiosis-specific cohesin complex implicated in the cohesin code for homologous pairing. EMBO J 2011, 12:267-275.

35. Nasmyth K, Haering $\mathrm{CH}$ : Cohesin: its roles and mechanisms. Annu Rev Genet 2009, 43:525-558.

36. Ishibashi T, Kimura S, Furukawa T, Hatanaka M, Hashimoto J, Skaguchi K: Two types of replication protein A $70 \mathrm{kDa}$ subunit in rice, Oryza sativa: molecular cloning, characterization, and cellular \& tissue distribution. Gene 2001, 272:335-343.

37. Dalmay $T$, Horsefield R, Braunstein TH, Baulcombe DC: SDE3 encodes an RNA helicase required for post-transcriptional gene silencing in Arabidopsis. EMBO J 2001, 20:2069-2078.

38. Walstrom KM, Schmidt D, Bean CJ, Kelly WG: RNA helicase A is important for germline transcriptional control, proliferation, and meiosis in $C$. elegans. Mech Dev 2005, 122:707-720.

39. Kuroda MI, Kernan MJ, Kreber R, Ganetzky B, Baker BS: The maleless protein associates with the $\times$ chromosome to regulate dosage compensation in Drosophila. Cell 1991, 66:935-947.

40. Zhang S, Buder K, Burkhardt C, Schlott B, Görlach M, Grosse F: Nuclear DNA helicase II/RNA helicase A binds to filamentous actin. J Biol Chem 2002, 277:843-853

41. Tang X, Zhang Z, Zhang W, Zhao X, Li X, Zhang D, Liu Q, Tang W: Global gene profiling of laser-captured pollen mother cells indicates molecular pathways and gene subfamilies involved in rice meiosis. Plant Physiol 2010, 154:1855-1870.

42. Chen C, Farmer AD, Langley RJ, Mudge J, Crow JA, May GD, Huntley J, Smith AG, Retzel EF: Meiosis-specific gene discovery in plants: RNA-Seq applied to isolated Arabidopsis male meiocytes. BMC Plant Biol 2010, 10:280.

43. Nonomura K, Morohoshi A, Nakano M, Eiguchi M, Miyao A, Hirochika $H_{\text {, }}$ Kurata N: A germ cell-specific gene of the ARGONAUTE family is essential for the progression of premeiotic mitosis and meiosis during sporogenesis in rice. Plant Cell 2007, 19:2583-2594.

44. Yang M, Hu Y, Lodhi M, McCombie WR, Ma H: The Arabidopsis SKP1-LIKE1 gene is essential for male meiosis and may control homologue separation. Proc Natl Acad Sci USA 1999, 96:11416-11421.

45. Bugreev DV, Pezza RJ, Mazina OM, Voloshin ON, Camerini-Otero RD, Mazin AV: The resistance of DMC1 D-loops to dissociation may account for the DMC1 requirement in meiosis. Nat Struct Mol Biol 2011, 18:56-60.

46. Higgins JD, Armstrong SJ, Franklin FC, Jones GH: The Arabidopsis MutS homolog AtMSH4 functions at an early step in recombination: evidence for two classes of recombination in Arabidopsis. Genes Dev 2004, 18:2557-2570.

47. Higgins JD, Sanchez-Moran E, Armstrong SJ, Jones GH, Franklin FC: The Arabidopsis synaptonemal complex protein ZYP1 is required for chromosome synapsis and normal fidelity of crossing over. Genes Dev 2005, 19:2488-2500.

48. Chang $\mathrm{L}, \mathrm{Ma} \mathrm{H}$, Xue HW: Functional conservation of the meiotic genes SDS and RCK in male meiosis in the monocot rice. Cell Res 2009, 19:768-782.

49. Sieburth LE, Running MP, Meyerowitz EM: Genetic separation of third and fourth whorl functions of AGAMOUS. Plant Cell 1995, 7:1249-1258.

50. Vitulo N, Vezzi A, Galla G, Citterio S, Marino G, Ruperti B, Zermiani M, Albertini E, Valle G, Barcaccia G: Characterization and evolution of the cell cycle-associated Mob domain-containing proteins in eukaryotes. Evol Bioinformatics 2007, 3:121-158.

51. Wang Z, Hu H, Huang H, Duan K, Wu Z, Wu P: Regulation of OsSPX1 and OsSPX3 on expression of OsSPX domain genes and Pi-starvation signaling in rice. J Integr Plant Biol 2009, 51:663-674.

52. Peragine A, Yoshikawa M, Wu G, Albrecht HL, Poethig RS: SGS3 and SGS2/ SDE1/RDR6 are required for juvenile development and the production of trans-acting siRNAs in Arabidopsis. Genes Dev 2004, 18:2368-2379.

53. Yang X, Makaroff CA, Ma H: The Arabidopsis MALE MEIOCYTE DEATH1 gene encodes a PHD-finger protein that is required for male meiosis. Plant Cell 2003, 15:1281-1295.

54. Osman K, Sanchez-Moran E, Higgins JD, Jones GH, Franklin FCH: Chromosome synapsis in Arabidopsis: analysis of the transverse filament protein ZYP1 reveals novel functions for the synaptonemal complex. Chromosoma 2006, 115:212-219.

55. Carman JG, Jamison M, Elliott E, Dwivedi KK, Naumova TN: Apospory appears to accelerate onset of meiosis and sexual embryo sac formation in sorghum ovules. BMC Plant Biol 2011, 11:9.

56. Opresko PL, von Kobbe C, Laine JP, Harrigan J, Hickson ID, Bohr VA: Telomere-binding protein TRTF2 binds to and stimulates the Werner and Bloom syndrome helicases. J Biol Chem 2002, 277:41110-41119.

57. $\mathrm{Ma} \mathrm{H}$ : Molecular genetic analyses of microsporogenesis and microgametogenesis in flowering plants. Annu Rev Plant Biol 2005, 56:393-434.

58. Mercier R, Grelon M: Meiosis in plants: ten years of gene discovery. Cytogenet Genome Res 2008, 120:281-290.

59. Bishop DK, Park D, Xu L, Kleckner N: DMC1: A meiosis-specific yeast homolog of $E$. coli recA required for recombination, synaptonemal complex formation, and cell cycle progression. Cell 1992, 69:439-456.

60. Klimyuk VI, Jones JDG: AtDMC1, the Arabidopsis homologue of the yeast DMC1 gene: Characterization, transposon-induced allelic variation and meiosis-associated expression. Plant J 1997, 11:1-14.

61. Kathiresan A, Khush GS, Bennett J: Two rice DMC1 genes are differentially expressed during meiosis and during haploid and diploid mitosis. Sex Plant Reprod 2002, 14:257-267.

62. Ronceret A, Doutriaus M-P, Golubovskaya IN, Pawlowski WP: PHS1 regulates meiotic recombination and homologous chromosome pairing by controlling the transport of RAD50 to the nucleus. Proc Natl Acad SCi USA 2009, 106:20121-20126. 
63. Li J, Harper LC, Golubovskaya I, Wang CR, Weber D, Meeley RB, McElver J, Bowen B, Cande WZ, Schnable PS: Functional analysis of maize RAD51 in meiosis and double-strand break repair. Genetics 2007, 176:1469-1482.

64. Chikashige Y, Ding DQ, Imai Y, Yamaoto M, Harguchi T, Hiraoka Y: Meiotic nuclear reorganization: switching the position of centromeres and telomeres in the fission yeast Schizosaccharomyces pombe. EMBO J 1997, 16:193-202.

65. Sheehan MJ, Pawlowski : Live imaging of rapid chromosome movements in meiotic prophase I in maize. Proc Natl Acad Sci USA 2009, 106:20989-20994.

66. Bhatt AM, Zhang Q, Harris SA, White-Cooper H, Dickinson H: Gene structure and molecular analysis of Arabidopsis thaliana ALWAYS EARLY homologs. Gene 2004, 336:219-229.

67. Armstrong L, Lako M, van Herpe I, Evans J, Sartzki G, Hole N: A role for nucleoprotein Zap3 in the reduction of telomerase activity during embryonic stem cell differentiation. Mech Dev 2004, 121:1509-1522.

68. Vernos I, Raats J, Hirano T, Heasman J, Karsenti E, Wylie C: Xklp1, a chromosomal Xenopus kinesin-like protein essential for spindle organization and chromosome positioning. Cell 1995, 81:117-127.

69. D'Erfurth I, Jolivet S, Froger N, Catrice O, Novatchkova M, Mercier R: Turning meiosis into mitosis. PloS Biol 2009, 7:e1000124.

70. Albertini E, Marconi G, Reale L, Barcaccia G, Porceddu A, Ferranti F, Falcinelli M: SERK and APOSTART. Candidate genes for apomixis in Poa pratensis. Plant Physiol 2005, 138:2185-2199.

71. Libeau P, Durandet M, Granier F, Marquis C, Berthomé R, Renou JP, Taconnat-Soubirou Horlow C: Gene expression profiling of Arabidopsis meiocytes. Plant Biol 2011, 13:784-793.

72. Chang MT, Neuffer MG: A simple method for staining nuclei of mature and germinated maize pollen. Stain Technology 1989, 64:181-184.

73. Smyth GK: Linear models and empirical Bayes methods for assessing differential expression in microarray experiments. Stat Appl Genet Mol Biol 2004, 3, Article3.

74. Ma J, Duncan D, Morrow D, Fernandes J, Walbot V: Transcriptome profiling of maize anthers using genetic ablation to analyze pre-meiotic and tapetal cell types. Plant J 2007, 50:637-648.

75. Zhao S, Fernald RD: Comprehensive algorithm for quantitative real-time polymerase chain reaction. J Comput Biol 2005, 12:1045-1062.

doi:10.1186/1471-2229-11-120

Cite this article as: Nan et al: Global transcriptome analysis of two ameiotic1 alleles in maize anthers: defining steps in meiotic entry and progression through prophase I. BMC Plant Biology 2011 11:120.

\section{Submit your next manuscript to BioMed Central and take full advantage of:}

- Convenient online submission

- Thorough peer review

- No space constraints or color figure charges

- Immediate publication on acceptance

- Inclusion in PubMed, CAS, Scopus and Google Scholar

- Research which is freely available for redistribution

Submit your manuscript at www.biomedcentral.com/submit
Biomed Central 